\title{
A Risk Assessment Model for Banks
}

\author{
Charles A.E. Goodhart \\ Bank of England, London School of Economics, \\ and Financial Markets Group \\ Pojanart Sunirand \\ Bank of England and \\ London School of Economics \\ Dimitrios P. Tsomocos \\ Bank of England, Said Business School \\ and St. Edmund Hall, University of Oxford, and \\ Financial Markets Group
}

First version: 8 March 2004

This version: 28 June 2004

\begin{abstract}
The objective of this paper is to propose a model to assess risk for banks. Its main innovation is to incorporate endogenous interaction between banks, recognising that the actual risk to which an individual bank is exposed also depends on its interaction with other banks and other private sector agents. To this end, we develop a two-period general equilibrium model with three active heterogeneous banks, incomplete markets, and endogenous default. The setting of three heterogeneous banks allows us to study not only interaction between any two individual banks, but also their interaction with the rest of the banks in the banking system. We show that the model is analytically tractable and can be calibrated against real UK banking data and therefore can be implemented as a risk assessment tool for financial regulators and central banks. We address the impact of monetary and regulatory policy as well as credit and capital shocks in the real and financial sectors.

JEL Classification: C68; E4; E5; G11; G21

Keywords: Financial Fragility; Financial Contagion; Systemic Risk; Banks; Monetary Policy; Regulatory Policy; Equilibrium Analysis
\end{abstract}

\section{Introduction}

The objective of this paper is to propose a model to assess risk for banks. Existing models for this purpose, e.g. stress-testing models, focus almost entirely on individual institutions. ${ }^{1}$ The major flaw of these models is that they fail to recognise that the actual risk to which an individual bank is exposed also depends on its interaction with other banks and other private sector agents and therefore is endogenous. This endogeneity aspect of risk may matter enormously in times of financial crises; a negative shock which is ex ante specific to a particular bank can produce a serious strain on others through a series of interactive contagion effects. The main innovation of our approach, therefore, is to take into account such endogenous interaction between banks, particularly through their mutual exposures in the interbank market. To this end, we require a set-up which can incorporate heterogeneous banks, each with a unique

\footnotetext{
${ }^{1}$ An exception is, for example, an approach developed in Elsinger, Lehar and Summer (2003).
} 
risk/return portfolio; if they were identical, there would be no interbank market by definition. We also need default to exist, since if there were no default, there would be no crises. Moreover, financial markets cannot be complete. Otherwise banks can always hedge themselves against all kinds of shocks, in which case, there would, again, be no crises. We have constructed a two-period general equilibrium model along these lines in Goodhart, Sunirand, and Tsomocos (2003).

We show in Goodhart et al. (2003) that an equilibrium exists in such model and that financial fragility emerges naturally as an equilibrium phenomenon. However, given the scale of the model which contains $B$ heterogeneous banks, $H$ private sector agents, $S$ possible states, a variety of financial assets and default, it is impossible to find either a closed-form or a numerical solution to this general model. In Goodhart, Sunirand, and Tsomocos (2004), we therefore present a simplified version of our general model and show that it can be solved numerically. This implies that the model, in some sense, 'works' and can, in principle, be used to assess various policies for crisis management. However, the model was solved on the basis of an arbitrarily chosen set of initial conditions. The outcome, therefore, is a somewhat artificial construct of our own assumed inputs. In this paper, we take a step further by attempting to calibrate an alternative version of our general model against real UK banking data. Thus, we argue that our model is not only rich enough to incorporate endogenous interaction between banks, but it is also sufficiently flexible to be implemented as a risk assessment tool for financial regulators and central banks.

The model presented in Goodhart et al. (2004) has two heterogeneous banks. A banking system, however, generally comprises multiple banks. Thus, although the model can be used to study interaction between any two individual banks, its level of complexity is not sufficient to incorporate contagion effects arising from their interaction with the rest of the banking sector. In this paper, we therefore introduce an additional bank, which can be thought of as the aggregation of the remaining banks in the system. Given the lack of disaggregated household and investors' portfolio data, we model household behaviour via reduced-form equations which relate their actions to a variety of economic variables such as GDP, interest rates, and aggregate credit supply etc. In this sense, our model is a partially-microfounded general equilibrium model. ${ }^{2}$ However, the main aspects of equilibrium analysis which are market clearing, rational expectation, and agent optimisation are maintained. Moreover, contagion effects between the banking sector and the real economy still operate actively in equilibrium via the reduced-form equations. Thus, we adhere to the general equilibrium spirit of Goodhart et al. (2003 and 2004). The upshot of our modelling framework is that financial decisions generate real effects in the rest of the macroeconomy. Our model is therefore amenable to welfare analysis.

The rest of the paper is structured as follows. The next section presents the model. Section 3 then explains how the model is calibrated against UK banking data. Section 4 provides a stress-testing analysis for the UK banking sector. Section 5 presents a robustness check of the result obtained in section 4 . The final section provides concluding remarks.

\section{The Model}

The model has three heterogeneous banks, $b \in B=\{\gamma, \delta, \tau\}$, four private sector agents, $h \in H=\{\alpha, \beta, \theta, \phi\}$, a Central Bank and a regulator. The time horizon extends over two periods, $t \in T=\{1,2\}$ and two possible states in the second period, $s \in S=\{i, i i\}$. We

\footnotetext{
${ }^{2}$ As is shown in Goodhart et al. (2004), household and investor optimisation problem can be easily introduced. However, owing to the limited availability of disaggregated household data, we chose not to follow that route.
} 


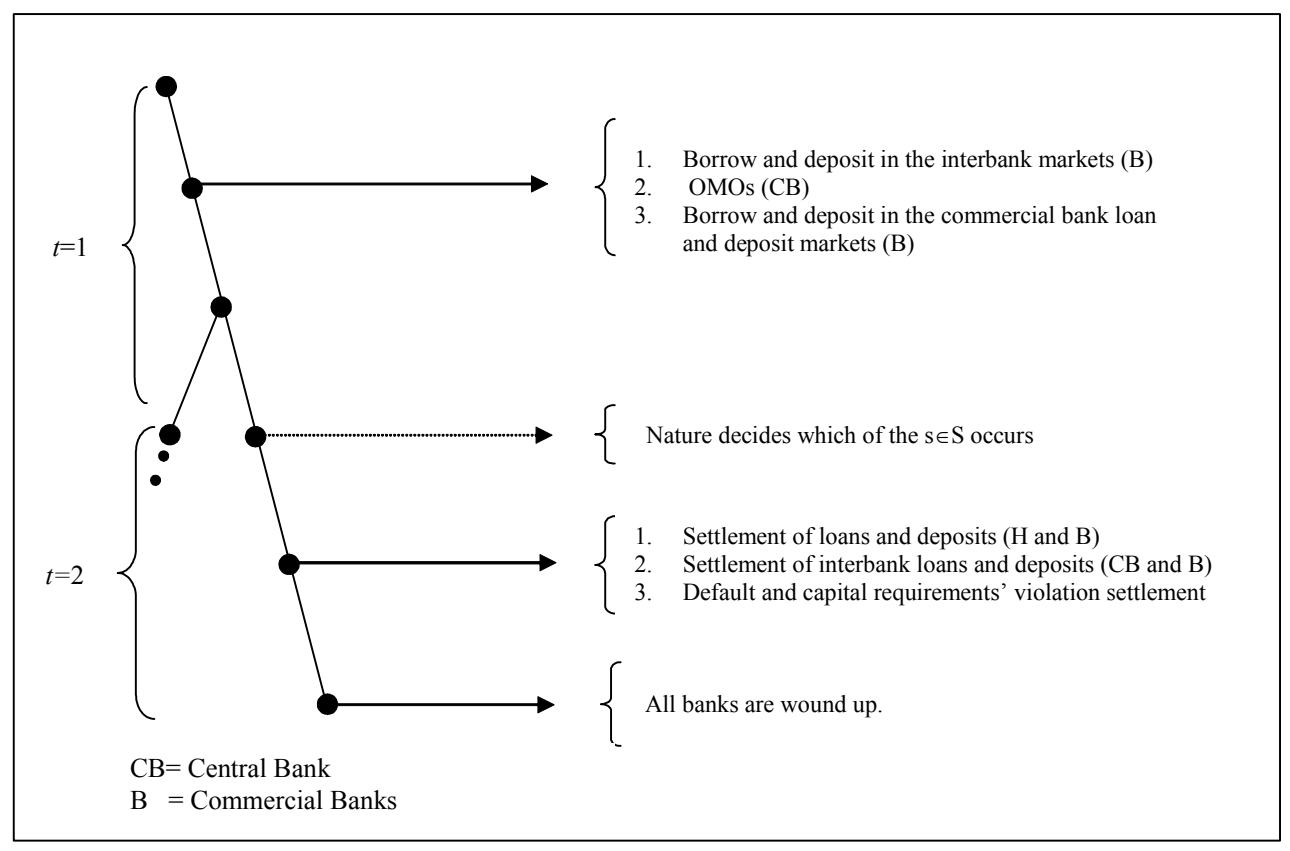

Figure 1: The time structure of the model

assume that state $i$ is a normal/good state whereas state $i i$ represents an extreme/crisis event. The probability that state $i$ will occur is denoted by $p$.

As in Goodhart et al. (2003 and 2004), we assume that individual bank borrowers are assigned during the two periods, by history or by informational constraint, to borrow from a single bank (i.e. a limited participation assumption). ${ }^{3}$ Given this assumption, together with our set-up of a system of three heterogeneous banks, we need at least three borrowers. We therefore assume that agents $\alpha, \beta$, and $\theta$ borrow from banks $\gamma, \delta$, and $\tau$, respectively. The remaining agent, Mr. $\phi$, represents the pool of depositors in this economy which supplies funds to every bank. This implies that we have multiple active markets for deposits (by separate bank) and for loans (by borrower and bank). In addition, we also assume a single, undifferentiated, interbank market where deficit banks are allowed to borrow from surplus banks, and wherein the Central Bank conducts open market operations (OMOs).

The time structure of the model is presented in figure 1 . At $t=1$, loan, deposit and interbank markets open. Banks decide how much to lend/borrow in each market, expecting rationally any one of the two possible future scenarios to be realised. Moreover, the Central Bank also conducts OMOs in the interbank market. At $t=2$, depending on the state which actually occurs, all financial contracts are settled, subject to any defaults and/or capital requirements' violations, which are then penalised. At the end of the second period, all banks are wound up.

\footnotetext{
${ }^{3}$ In Bhattacharya, Goodhart, Sunirand and Tsomocos (2003) we show that restricted participation in the loan market can also arise as an equilibrium outcome given that the objective functions of banks also include a relative performance criterion, i.e. a preference to outperform their competitors.
} 


\subsection{Banking Sector: UK banks}

Without loss of generality, our specification of the banking sector is based on the UK banking sector, which we assume to comprise of seven largest UK banks; Lloyds, HSBC, Abbey National, HBOS, Barclays, Royal Bank of Scotland, and Standard Chartered. Banks $\gamma$ and $\delta$ can represent any two of these individual banks, whereas bank $\tau$ represents the aggregation of the remaining banks. As will be explained more below, in our calibration exercise, banks $\gamma$ and $\delta$ are chosen specifically to represent two of these actual UK banks. However, for data confidentiality reason, we do not reveal their identities.

All banks in the model, $b \in B=\{\gamma, \delta, \tau\}$, are assumed to operate under a perfectly competitive environment (i.e. they take all interest rates as exogenously given when making their optimal portfolio decisions). The structure of their balance sheets is given below;

\begin{tabular}{|l|l|}
\hline Assets & Liabilities \\
\hline Loans to agents & Deposits from Mr. $\phi$ \\
Interbank deposits & Interbank borrowing \\
Market book & Equity \\
& Others \\
\hline
\end{tabular}

We assume that all banks endogenise their decisions in the loan, deposit and interbank markets. ${ }^{4}$ The remaining variables are treated as exogenous. ${ }^{5}$ We further assume that banks in our model can default on their financial obligations, subject to default penalties set by the regulator. Thus, by varying the penalties imposed on default from 0 to infinity, we can model $100 \%$ default, no default or an equilibrium level of default between 0 and $100 \% .{ }^{6}$ At first sight, this 'continuous' default rate approach may seem problematic since in reality banks either repay in full at the due date or are forced to close down. However, we interpret a bank's default rate in our model as a probability that such bank chooses to shut down, and hence in the short run to default completely on its financial obligations. For example, a default rate of 4 percent implies that there is roughly a 4 percent chance of a shut down and a 96 percent chance that the bank will repay in full and continue its normal operation. Therefore, a bank's decision to increase its default rates is isomorphic to its decision to adopt a riskier position in pursuit of higher expected profitability. ${ }^{7}$ Finally, as in Bhattacharya et al. (2003), we make a simplifying assumption by assuming that banks' default rates in the deposit and interbank markets are the same, i.e. banks are restricted to repay all their creditors similarly.

Analogous to the modelling of default, banks can violate their capital adequacy requirement, subject to capital requirement violation penalties set by the regulator. In principle, each bank's effective capital to asset ratios may not be binding, (i.e. their values may be above the regulator's requirement), in which case they are not subject to any capital requirement

\footnotetext{
${ }^{4}$ The modelling of the banking sector follows Shubik and Tsomocos (1992) and Tsomocos (2003a and b).

${ }^{5}$ Given the present set-up, we cannot endogenise banks' decisions on market book or equity. This is because the model has two states in the second period and one unconstrained asset (i.e. an asset that banks can either go infinitely short or long), which is the interbank market investment. By adding another unconstrained asset, markets would be complete. In principle, our model can be extended to incorporate additional states in the second period and therefore can be used to study the economic effects on the market (trading) book. For example, we can disaggregate the market book into two components according to their riskiness (or rating) and endogenise banks' decisions on these variables. This would allow us to study the endogenous response of risk premia on corporate debt to a series of shocks. However, we face a practical problem on this front since there are insufficient data on the composition of the market book by category, e.g. rating maturity, and currency.

${ }^{6}$ This modelling of default follows Shubik and Wilson (1977).

${ }^{7}$ For more on this issue, see work in progress by Tsomocos and Zicchino (2004).
} 
penalty. However, in our calibration exercise, we assume for simplicity that each bank wants to keep a buffer above the required minimum, so that there is a non-pecuniary loss of comfort and reputation as capital declines; in this sense the ratios are always binding. Put differently, we assume that banks' self-imposed ideal capital holdings are always above the actual values of all banks' capital to asset ratios. Given this assumption, we can rule out corner equilibria and therefore focus our analysis entirely on well-defined interior solutions whereby banks violate their enhanced capital requirements. We assume that penalties are linear as capital declines from its ideal level. In practice, there will be some non-linearity as capital falls below its required minimum, but this is just too complex to model at this stage.

As will be elaborated in section 3, our calibration exercise is based on the data of UK banks at the end of 2002. At that point in time, bank $\delta$ is a net lender whereas banks $\gamma$ and $\tau$ are net borrowers in the interbank market. ${ }^{8}$ Given this setting, we describe the optimisation problems of these banks below.

\subsubsection{The interbank net borrowers' (banks $\gamma$ and $\tau$ ) optimisation problems}

Bank $b \in\{\gamma, \tau\}$ maximises its payoff, which is a quadratic function of its expected profitability in the second period minus non-pecuniary penalties that it has to incur if it defaults on its deposit and interbank obligations. It also suffers a capital violation penalty proportional to its capital requirement violation. Formally, the optimisation problem of bank $b \in\{\gamma, \tau\}$ is as follows;

$$
\max _{\bar{m}^{b}, \mu^{b}, \mu_{d}^{b}, v_{s}^{b}, s \in S} \Pi^{b}=\sum_{s \in S} p_{s}\left[\frac{\pi_{s}^{b}}{10^{10}}-c_{s}^{b}\left(\frac{\pi_{s}^{b}}{10^{10}}\right)^{2}\right]-\sum_{s \in S} p_{s}\left[\begin{array}{c}
\lambda_{k s}^{b} \max \left[0, \bar{k}^{b}-k_{s}^{b}\right]+ \\
\frac{\lambda_{s}^{b}}{10^{10}}\left[\mu^{b}-v_{s}^{b} \mu^{b}\right]+\frac{\lambda_{s}^{b}}{10^{10}}\left[\mu_{d}^{b}-v_{s}^{b} \mu_{d}^{b}\right]
\end{array}\right]
$$

subject to

$$
\begin{aligned}
\bar{m}^{b}+A^{b} & =\frac{\mu^{b}}{(1+\rho)}+\frac{\mu_{d}^{b}}{\left(1+r_{d}^{b}\right)}+e_{0}^{b}+\text { Other }^{b} \\
\pi_{s}^{b} & =v_{s b}^{h^{b}}\left(1+r^{b}\right) \bar{m}^{b}+\left(1+r^{A}\right) A^{b}-\left(v_{s}^{b} \mu^{b}+v_{s}^{b} \mu_{d}^{b}+\text { Others }^{b}+e_{0}^{b}\right), s \in S \\
e_{s}^{b} & =e_{0}^{b}+\pi_{s}^{b}, s \in S \\
k_{s}^{b} & =\frac{e_{s}^{b}}{\bar{\omega} v_{s b}^{h^{b}}\left(1+r^{b}\right) \bar{m}^{b}+\widetilde{\omega}\left(1+r^{A}\right) A^{b}}, s \in S
\end{aligned}
$$

where,

$p_{s} \equiv$ probability that state $s \in S$ will occur,

$c_{s}^{b} \equiv$ coefficient of risk aversion in the utility function of bank $b \in B$,

$\lambda_{k s}^{b} \equiv$ capital requirements' violation penalties imposed on bank $b \in B$ in state $s \in S$,

$\bar{k}^{b} \equiv$ capital adequacy requirement for bank $b \in B$,

$\lambda_{s}^{b} \equiv$ default penalties on bank $b \in B$,

$\mu^{b} \equiv$ amount of money that bank $b \in\{\gamma, \tau\}$ owes in the interbank market,

$\mu_{d}^{b} \equiv$ amount of money that bank $b \in B$ owes in the deposit market,

\footnotetext{
${ }^{8}$ As noted earlier, we have chosen banks $\gamma$ and $\delta$ to represent specifically two of the seven largest UK banks in our calibration exercise. Bank $\tau$ then represents the aggregation of the remaining five banks.
} 
$v_{s}^{b} \equiv$ repayment rates of bank $b \in B$ to all its creditors in state $s \in S$,

$\bar{m}^{b} \equiv$ amount of credit that bank $b \in B$ extends in the loan market,

$A^{b} \equiv$ the value of market book held by bank $b \in B$,

$e_{s}^{b} \equiv$ amount of capital that bank $b \in B$ holds in state $s \in\{0\} \cup S$,

Others ${ }^{b} \equiv$ the 'others' item in the balance sheet of bank $b \in B$,

$r^{b} \equiv$ lending rate offered by bank $b \in B$,

$r_{d}^{b} \equiv$ deposit rate offered by bank $b \in B$,

$\rho \equiv$ interbank rate,

$r^{A} \equiv$ the rate of return on market book,

$v_{s b}^{h^{b}} \equiv$ repayment rates of agent $h^{b} \in H^{b}=\left\{\alpha^{\gamma}, \beta^{\delta}, \theta^{\tau}\right\}$ to his nature-selected bank $b \in B$ in the consumer loan market,

$\bar{\omega} \equiv$ risk weight on consumer loans, and

$\widetilde{\omega} \equiv$ risk weight on market book.

Equation (1) implies that, at $t=1$, the assets of bank $b \in\{\gamma, \tau\}$, which consist of its credit extension and market book investment, must be equal to its liabilities obtained from interbank and deposit borrowing and its initial equity endowment, where 'Other $s^{b}$ ' represents the residual. Equation (2) then shows that, dependent on which of the $s \in S$ actually occurs, the profit that bank $b$ incurs in the second period is equal to the difference between the amount of money that it receives from its asset investment and the amount that it has to repay on its liabilities, adjusted appropriately for default in each market. As shown in equation (3), this profit earned is then added to its initial capital, which in turn becomes its capital in the second period. Finally, equation (4) implies that the capital to asset ratio of bank $b$ in state $s \in S$ is equal to its capital in state $s$ divided by its risk-weighted assets in the corresponding state.

\subsubsection{The interbank net lender's (bank $\delta$ ) optimisation problem}

Bank $\delta$, unlike the other two banks, is a net lender in the interbank market. Thus it suffers only a default penalty in the deposit market. Formally, bank $\delta$ 's optimisation problem is as follows;

$\max _{\bar{m}^{\delta}, d^{\delta}, \mu_{d}^{\delta}, v_{s}^{\delta}, s \in S} \Pi^{\delta}=\sum_{s \in S} p_{s}\left[\frac{\pi_{s}^{\delta}}{10^{10}}-c_{s}^{\delta}\left(\frac{\pi_{s}^{\delta}}{10^{10}}\right)^{2}\right]-\sum_{s \in S} p_{s}\left[\lambda_{k s}^{\delta} \max \left[0, \bar{k}^{\delta}-k_{s}^{\delta}\right]+\frac{\lambda_{s}^{\delta}}{10^{10}}\left[\mu_{d}^{\delta}-v_{s}^{\delta} \mu_{d}^{\delta}\right]\right]$

subject to

$$
\begin{aligned}
A^{\delta}+d^{\delta}+\bar{m}^{\delta} & =e_{0}^{\delta}+\frac{\mu_{d}^{\delta}}{\left(1+r_{d}^{\delta}\right)}+\text { Others }^{\delta} \\
\pi_{s}^{\delta} & =v_{s \delta}^{\beta^{\delta}} \bar{m}^{\delta}\left(1+r^{\delta}\right)+A^{\delta}\left(1+r^{A}\right)+\widetilde{R}_{s} d^{\delta}(1+\rho)-\left(v_{s}^{\delta} \mu_{d}^{\delta}+\text { Other }^{\delta}+e_{0}^{\delta}\right) \\
e_{s}^{\delta} & =e_{0}^{\delta}+\pi_{s}^{\delta} \\
k_{s}^{\delta} & =\frac{e_{s}^{\delta}}{\bar{\omega} v_{s \delta}^{\beta^{\delta}}\left(1+r^{\delta}\right) \bar{m}^{\delta}+\omega \widetilde{R}_{s} d^{\delta}(1+\rho)+\widetilde{\omega}\left(1+r^{A}\right) A^{\delta}}
\end{aligned}
$$

where,

$d^{\delta} \equiv$ bank $\delta$ 's investment in the interbank market, 
$\widetilde{R}_{s} \equiv$ the rate of repayment that bank $\delta$ expects to get from its interbank investment, and

$\omega \equiv$ risk weight on interbank investment.

The budget set of bank $\delta$ is similar to those of the other two banks except that it invests in, instead of borrows from, the interbank market. Moreover, its risk-weighted assets in the second period, as shown in equation (8), also includes bank $\delta$ 's expected return on its interbank investment.

\subsection{Central Bank and Regulator}

The Central Bank's and the regulator's decisions are exogenous. The Central Bank and the regulator may, but need not, be a single institution. The Central Bank conducts monetary policy by engaging in open market operations in the interbank market. We assume as our baseline specification that the Central Bank sets its base money $(M)$ as its monetary policy instrument, allowing the interbank rate to be determined endogenously. However, as will be seen in section 3 , we also consider an alternative instrument targeting regime whereby the Central Bank fixes the interbank rate and lets its base money adjust endogenously to clear the interbank market. As will be explained below, the simulation results depend crucially on which monetary policy instrument the Central Bank employs. Therefore, whether monetary authorities target base money or the interbank rates in response to shocks has different implications with respect to financial stability.

The regulator sets capital adequacy requirements for all banks $\left(\bar{k}^{b}, b \in B\right)$ as well as imposes penalties on their failures to meet such requirements $\left(\lambda_{k s}^{b}, b \in B, s \in S\right)$ and on default on their financial obligations in the deposit and interbank markets $\left(\lambda_{s}^{b}, b \in B, s \in S\right)$. Finally, he also sets the risk weights on consumer loan, interbank and market book investment $(\bar{\omega}, \omega, \widetilde{\omega})$.

\subsection{Private agent sector}

Each household borrower, $h^{b} \in H^{b}=\left\{\alpha^{\gamma}, \beta^{\delta}, \theta^{\tau}\right\}$, demands consumer loans from his natureselected bank $b$ and chooses whether to default on his loans in state $s \in S$. The remaining agent, Mr. $\phi$, supplies his deposits to each bank $b \in B$. As mentioned, we do not explicitly model the optimisation problems of households. The reason is that it is very difficult, if at all possible, to find real data for the (heterogeneous) private agent sector, e.g. the monetary and good endowment of each banks's borrowers and depositors. This latter is particularly important since one of the key objectives of this paper is take our model to real data. So, instead of explicitly providing microfoundations for households' decisions, we 'artificially' endogenise them by assuming the following reduced-form equations.

\subsubsection{Household Borrowers' Demand for Loans}

Because of the limited participation assumption in every consumer loan market, each household's demand for loans is a negative function of the lending rate offered by his nature-selected bank. In addition, his demand for loans also depends positively on the expected GDP in the subsequent period. Put differently, we implicitly assume that household borrowers rationally anticipate GDP in both states of the next period, which then determines their expected future income, and adjust their loan demand in this period accordingly in order to smooth their consumption over time. As in Goodhart et al. (2003, 2004), our money demand function manifests the standard Hicksian elements whereby it responds positively to current and expected 
income and negatively to interest rates. In particular, we assume the following functional form of household $h^{b}$ 's loan demand from his nature-selected bank $b, \forall h^{b} \in H^{b}$, and $b \in B$.

$$
\ln \left(\mu^{h^{b}}\right)=a_{h^{b}, 1}+a_{h^{b}, 2} \ln \left[p\left(G D P_{i}\right)+(1-p) G D P_{i i}\right]+a_{h^{b}, 3} r^{b}
$$

where,

$\mu^{h^{b}} \equiv$ amount of money that agent $h^{b} \in H^{b}$ chooses to owe in the loan market of bank $b \in B$, and

$G D P_{s} \equiv$ Gross Domestic Product in state $s \in S$ of the second period.

\subsubsection{Mr. $\phi$ 's Supply of Deposits}

Unlike the loan markets, we do not assume limited participation in the deposit markets. This implies that Mr. $\phi$ can choose to diversify his deposits with every bank. Thus, Mr. $\phi$ 's deposit supply with bank $b$ depends not only on the deposit rate offered by bank $b$ but also on the rates offered by the other banks. Moreover, since banks in our model can default on their deposit obligations, the expected rate of return on deposit investment of Mr. $\phi$ with bank $b$ has to be adjusted appropriately for its corresponding expected default rate. Finally, Mr. $\phi$ 's deposit supply is a positive function of the expected GDP in the subsequent period.

In sum, since his deposit decisions determine his investment portfolio, given the expected rates of return, he diversifies among the existing deposit markets. Mr. $\phi$ 's deposit supply function with bank $b, \forall b \in B$, is as follows;

$$
\begin{aligned}
\ln \left(d_{b}^{\phi}\right)= & z_{b, 1}+z_{b, 2} \ln \left[p\left(G D P_{i}\right)+(1-p) G D P_{i i}\right]+z_{b, 3}\left[r_{d}^{b}\left(p v_{i}^{b}+(1-p) v_{i i}^{b}\right)\right] \\
& +z_{b, 4} \sum_{\dot{b} \neq b \in B}\left[r_{d}^{\hat{b}}\left(p v_{i}^{\hat{b}}+(1-p) v_{i i}^{\hat{b}}\right)\right]
\end{aligned}
$$

where,

$d_{b}^{\phi} \equiv$ amount of money that agent $\phi$ chooses to deposit with bank $b \in B$.

\subsubsection{Households' Loan Repayment Rates}

We assume that each household's repayment rate on his loan obligation to his nature-selected bank in state $s \in S$ is a positive function of the corresponding GDP level as well as the aggregate credit supply in the economy. The latter variable captures the effect of 'credit crunch' in the economy whereby a fall in the overall credit supply in the economy aggravates the default probability of every household. ${ }^{9}$ Specifically, the functional form of the repayment rate of household $h^{b}, \forall h^{b} \in H^{b}$, to his nature-selected bank $b \in B$, in state $s \in S$ is as follows;

$$
\ln \left(v_{s b}^{h^{b}}\right)=g_{h^{b}, s, 1}+g_{h^{b}, s, 2} \ln \left(G D P_{s}\right)+g_{h^{b}, s, 3}\left[\ln \left(\bar{m}^{\gamma}\right)+\ln \left(\bar{m}^{\delta}\right)+\ln \left(\bar{m}^{\tau}\right)\right]
$$

\footnotetext{
${ }^{9}$ Higher interest rates, given that households are liquidity constrained, ultimately increase their debt obligations in the future. Hence, defaults rise.
} 


\subsection{GDP}

As can be seen from equations (9) to (11), we have assumed that households' actions depend on their expected GDP in the second period. So, in this section we endogenise GDP in both states of the second period. We assume that GDP in each state is a positive function of the aggregate credit supply available in the previous period. Since the Modigliani-Miller proposition does not hold in our mode ${ }^{10}$, higher credit extension as a result of loosening monetary policy, or any other shocks, generates a positive real balance effect that raises consumption demand and ultimately GDP. In particular, the following functional form for GDP in state $s \in S$ of the second period $\left(G D P_{s}\right)$ holds.

$$
\ln \left(G D P_{s}\right)=u_{s, 1}+u_{s, 2}\left[\ln \left(\bar{m}^{\gamma}\right)+\ln \left(\bar{m}^{\delta}\right)+\ln \left(\bar{m}^{\tau}\right)\right]
$$

\subsection{Market Clearing Conditions}

There are seven active markets in the model (three consumer loan, three deposit and one interbank markets). Each of these markets determines an interest rate that equilibrates demand and supply in equilibrium. ${ }^{11}$

$$
\begin{aligned}
1+r^{b} & =\frac{\mu^{h^{b}}}{\bar{m}^{b}}, h^{b} \in H^{b}, \forall b \in B \\
1+r_{d}^{b} & =\frac{\mu_{d}^{b}}{d_{b}^{\phi}}, \forall b \in B \\
1+\rho & =\frac{\mu^{\gamma}+\mu^{\tau}}{M+d^{\delta}}
\end{aligned}
$$

(i.e. bank $b$ 's loan market clears)

(i.e. bank b's deposit market clears) (14)

(i.e. interbank market clears) (15)

We note that these interest rates, i.e. $r^{b}, r_{d}^{b}$, and $\rho, b \in B$, are the ex ante nominal interest rates that incorporate default premium since default is permitted in equilibrium. Their effective ( $e x$ post) interest rates have to be suitably adjusted to account for default in their corresponding markets. ${ }^{12}$

\subsection{Equilibrium}

Let $\sigma^{b}=\left\{\bar{m}^{b}, \mu^{b}, \mu_{d}^{b}, v_{s}^{b}, \pi_{s}^{b}, e_{s}^{b}, k_{s}^{b}\right\} \in R_{+} \times R_{+} \times R_{+} \times R_{+}^{2} \times R^{2} \times R^{2} \times R^{2}$ for $b \in\{\gamma, \tau\}$; $\sigma^{\delta}=\left\{\bar{m}^{\delta}, d^{\delta}, \mu_{d}^{\delta}, v_{s}^{\delta}, \pi_{s}^{\delta}, e_{s}^{\delta}, k_{s}^{\delta}\right\} \in R_{+} \times R_{+} \times R_{+} \times R_{+}^{2} \times R^{2} \times R^{2} \times R^{2} ; \sigma^{h^{b}} \equiv\left(\mu^{h^{b}}, v_{s b}^{h^{b}}\right) \in$ $R_{+} \times R_{+}^{2}$ for $h^{b} \in H^{b}$ and ; $\sigma^{\phi} \equiv\left(d_{b}^{\phi}\right) \in R_{+}$for $b \in B$; and $G D P_{s} \in R^{2}$. Also, let $\eta \in$ $\left\{r^{\gamma}, r^{\tau}, r^{\delta}, r_{d}^{\gamma}, r_{d}^{\tau}, r_{d}^{\delta}, \rho\right\}, B^{b}(\eta)=\left\{\sigma^{b}:(1)-(4)\right.$ hold $\}$, and $B^{\delta}(\eta)=\left\{\sigma^{\delta}:(5)-(8)\right.$ hold \} . We say that $\left(\left(\sigma^{b}\right)_{b \in\{\gamma, \tau\}}, \sigma^{\delta}, \eta,\left(\sigma^{h^{b}}\right)_{h^{b} \in H^{b}}, \sigma^{\phi},\left(G D P_{s}\right)_{s \in S}\right)$ is a monetary equilibrium with commercial banks and default for the economy

$$
E\left\{\left(e_{0}^{b}, \text { Others }^{b}, A^{b}\right)_{b \in B} ; M ;\left(\bar{k}^{b}, \lambda_{s}^{b}, \lambda_{k s}^{b}, \bar{\omega}, \omega, \widetilde{\omega}\right)_{b \in B, s \in S} ; r^{A} ; p\right\}
$$

iff:

\footnotetext{
${ }^{10}$ See Goodhart et al. (2003) for an extensive discussion.

${ }^{11}$ The interest rate formation mechanism is identical to the offer-for-sale mechanism in Dubey and Shubik (1978). The denominator of each of the expressions (13-15) represents the supply side whereas the numerator divided by $(1+r), r \in\left\{r^{b}, r_{d}^{b}, \rho\right\}, b \in B$ corresponds to the demand. Note that this interest rate formation mechanism is well-defined both in, and out of, equilibrium.

${ }^{12}$ For more on the method of calculating the ex post interest rates, see Shubik and Tsomocos (1992).
} 
(i) (a) $\sigma^{b} \in \operatorname{Argmax} \Pi^{b}\left(\pi^{b}\right), b \in\{\gamma, \tau\}$

(b) $\sigma^{\delta} \in \underset{\sigma^{\delta} \in B^{\delta}(\eta)}{\operatorname{Argmax}} \Pi^{\delta}\left(\pi^{\delta}\right)$

(i.e. all banks optimise.)

(ii) All markets (13)-(15) clear.

(iii) $\widetilde{R}_{s}=\frac{\sum_{b \in\{\gamma, \tau\}} v_{s}^{b} \mu^{b}}{\sum_{b \in\{\gamma, \tau\}} \mu^{b}}, s \in S$

(i.e. bank $\delta$ is correct in its expectation about the repayment rates that it gets from its interbank investment.)

We emphasise here that the equilibrium conditions $(i)-($ iii $)$ are consistent with the defining properties of a competitive equilibrium with rational expectations.

(iv) $\sigma^{h^{b}}, \sigma^{\phi}$ and $G D P_{s}$, for $h \in H$ and $s \in S$ satisfy the reduced-form equations (9)-(12).

(i.e. loan demand, deposit supply, repayment rates, and GDP in both states satisfy the reduced-form equations (9)-(12))

\section{Calibration}

Excluding the Lagrange multipliers, conditions $(i)-(i v)$ in the previous section imply that we have a system of 56 simultaneous equations in 135 unknown variables, 79 of which are exogenous variables/parameters in the model. This implies that there are 79 variables whose values have to be chosen in order to obtain a numerical solution to the model. Thus, they represent the degrees of freedom in the system and can either be set appropriately or calibrated against the real data. It is important to note that these variables, which are exogenous when solving the system of simultaneous equations, do not necessarily have to be those which are exogenous in the model. ${ }^{13}$ We report the values of exogenous parameters/variables in the model and the resulting initial equilibrium in table I. The table also summarises whether the value of each variable reported is (1) calibrated against real data, (2) arbitrarily selected, or (3) endogenously solved. We note, however, that, owing to the data confidentiality reason, we suppress those numbers which are based on the calibrated balance sheet data of UK banks and replace them by ' $x x x$ ' in table I. Unless stated otherwise, the values of all the nominal variables reported therein, e.g. all bank balance sheet items, are normalised by $10^{10}$.

The values of all banks' balance sheet items in the initial period, i.e. $\left\{\bar{m}^{b}, \mu_{d}^{b} \text {, Other } s^{b}, A^{b}\right\}_{b \in B}$, $\left\{\mu^{b}\right\}_{b \in\{\gamma, \tau\}}$, and $\left\{d^{\delta}\right\}$, are calibrated using the 2002 annual account data for seven largest UK banks. Based on this source of data, we also calibrate the values of private agents' loan repayment rates to their nature-selected banks in the good/normal state, i.e. $\left(v_{i b}^{h^{b}}\right)_{h^{b} \in H^{b}}$, using each bank $b$ 's ratio of provision at the end of the year to total customer loans. However, since there are no data available for crisis/extreme events, the default rates of all private agents in the bad state (state $i$ ) are arbitrarily set to 0.1 .

\footnotetext{
${ }^{13}$ For example, the Central Bank in our model fixes its base money and lets the interbank interest rate adjust endogenously, i.e. base money is exogenous in the model. However, in solving for a numerical solution, we can first choose the value of the interbank rate and let the system of simultaneous equations determine endogenously the value of base money that supports the preset value of the interbank rate.
} 
The probability that state $i i$ will occur, $1-p$, is chosen to be 0.05 , given that it reflects an extreme event. Since banks rarely default on their debt obligations in the good state, the corresponding repayment rates in the deposit and interbank markets for all banks, i.e. $v_{i}^{b}, b \in B$, are set to 0.999 . In state $i i$, the bad state, we arbitrarily set the analogous repayment rates to 0.95 for banks $\gamma$ and $\tau$ and 0.955 for bank $\delta$. These values are selected to be relatively higher compared with households' repayment rates in state ii (0.9) since in reality the probability that banks would default on their financial obligations is smaller than that of households. Note also that the chosen value for bank $\delta$ 's repayment rate is slightly greater than those of the other two banks because its deposit rate, whose values are determined endogenously, is slightly smaller in equilibrium. This may suggest at first glance that we are assuming what we need to estimate, i.e. a bank's willingness to run a risky position, which could lead to enforced shut down. Not quite so, since each chosen value for a bank's chosen default rate relates to an equivalent subjective default penalty. If you give us, the model builders, some guidance on banks' aversion to default penalties, i.e. the size of the $\lambda_{s}^{b}, b \in B, s \in S$, we can adjust the default probabilities accordingly.

We choose the value of the interbank interest rate, $\rho$, to be 4 percent to match with the actual value of UK RP rate in December 2002. The value of risk weight for loans is set to 1 whereas the corresponding values for market book and interbank lending are 0.2. The value of capital to asset requirement set by the regulator for each bank $\left(\bar{k}^{b}, b \in B\right)$ is chosen to be slightly higher, but almost equal to, its corresponding value in state $i$ so that all banks always violate their capital requirement. ${ }^{14}$

The values of default and capital violation penalties $\left(\lambda_{s}^{b}\right.$ and $\lambda_{k s}^{b}, b \in B, s \in S$ ) reflect both the tightness of the regulator's regulatory policy and the (subjective) aversion of banks' managements to putting themselves at risk of default and/or regulatory violations, and can, in principle, be treated as inputs given by the practitioner users of this model. Their values are, however, unobservable and therefore have to be chosen somehow. We have chosen them in this example to be consistent with the following outcomes. First, the resulting endogenously-solved banks' lending rates are such that all banks earn positive profit in state $i$, whereas they suffer a loss in state $i$. This in turn implies that banks' capital at $t=2$ deteriorates if the bad state (ii) occurs. Second, all banks' coefficients of risk aversion $\left(c_{s}^{b}, b \in B, s \in S\right)$ are positive, implying that banks' utility functions are well-behaved, i.e. concave. Lastly, the rate of return on market book is arbitrarily chosen to be 4.5 percent.

We calibrate the value of GDP in the good state $\left(\mathrm{GDP}_{i}\right)$ to match with the actual UK (annual) GDP in 2002. We set the value of GDP in the bad state $\left(\mathrm{GDP}_{i i}\right)$ to represent a $4 \%$ fall from its corresponding value in the good state. The values of coefficients $a_{h^{b}, 2}$ and $a_{h^{b}, 3}$, $\forall h^{b} \in H^{b}$, in the reduced-form equation (9) are calibrated, respectively, using the values of the long-run income and interest rate elasticities of UK household sector estimated by Chrystal and Mizen (2001).

To our knowledge, we do not know any empirical study which estimates deposit supply and default probability functions for UK household/private sectors. Although this can, in principle, be done, such an exercise is beyond the scope of this paper. So, we arbitrarily choose the appropriate values of $z_{b, 2}, z_{b, 3}, z_{b, 4}, \forall b \in B$, in equation (10), and the values of $g_{h^{b}, s, 2}$ and $g_{h^{b}, s, 3}, \forall h^{b} \in H^{b}, s \in S$, in equation (11). As can be seen from table I, the values of $g_{h^{b}, i, 3}$

\footnotetext{
${ }^{14}$ As mentioned in section 2.1 , this is a simplifying assumption. Recall that capital requirements' violation penalty enters banks' objective functions as ' $\max \left[0, \bar{k}^{b}-k_{s}^{b}\right]$ '. However, given our assumption that banks always violate their capital requirement, we can restrict the optimisation problem to $\bar{k}^{b}-k_{s}^{b}>0$, thus avoiding 'corner'equilibria.
} 
is chosen to be greater than the corresponding values of $g_{h^{b}, i i, 3}, \forall h^{b} \in H^{b}$, implying that the effect of a 'credit crunch' is assumed to be stronger in the bad state.

The remaining parameters for which their values have to be chosen are the coefficients $u_{s, 2}$, $\forall s \in S$, in the reduced-form equation (12). We set them to be equal to 0.1. Because the value of these coefficients capture the inter-relationship between real and nominal variables in the economy, they are therefore important in determining the strength of the 'amplification' effect when a shock hits the economic system. For this reason, as will be seen in section 5, we conduct a robustness check by considering alternative initial values of these two parameters in our simulation exercise. At this point we note that the above specifications rely on the monetary and regulatory non-neutrality properties of our model. We formally prove these propositions in Goodhart et al. (2003).

Given the chosen values of the variables mentioned above, we are left with the system of 56 simultaneous equations in 56 unknown variables. By solving such system, the values of all the remaining variables are specified and a numerical solution to the model is obtained.

\begin{tabular}{|c|c|c|c|c|c|}
\hline \multicolumn{6}{|c|}{ Table I: Exogenous variables and the resulting initial equilibrium } \\
\hline & \multicolumn{3}{|c|}{ Initial Equilibrium } & \multicolumn{2}{|c|}{ Exogenous variables in the model } \\
\hline $\begin{array}{l}\text { Endogenously } \\
\text { solved }\end{array}$ & $\begin{aligned} r^{\gamma} & =0.0601 \\
r^{\delta} & =0.069 \\
r^{\tau} & =0.0615 \\
r_{d}^{\gamma} & =0.04 \\
r_{d}^{\delta} & =0.0357 \\
r_{d}^{\tau} & =0.04 \\
\mu_{d}^{\gamma} & =x x x \\
\mu_{d}^{\delta} & =x x x \\
\mu_{d}^{\tau} & =x x x \\
k_{i}^{\gamma} & =0.098 \\
k_{i i}^{\gamma} & =0.061\end{aligned}$ & $\begin{array}{l}k_{i}^{\delta}=0.155 \\
k_{i i}^{\delta}=0.147 \\
k_{i}^{\tau}=0.119 \\
k_{i i}^{\tau}=0.089 \\
\pi_{i}^{\gamma}=0.25 \\
\pi_{i i}^{\gamma}=-0.357 \\
\pi_{i}^{\delta}=0.327 \\
\pi_{i i}^{\delta}=-0.136 \\
\pi_{i}^{\tau}=2.1 \\
\pi_{i i}^{\tau}=-1.173 \\
e_{i}^{\gamma}=1.425\end{array}$ & $\begin{array}{l}e_{i i}^{\gamma}=0.818 \\
e_{i}^{\delta}=3.894 \\
e_{i i}^{\delta}=3.431 \\
e_{i}^{\tau}=10.58 \\
e_{i i}^{\tau}=7.307 \\
\widetilde{R}_{i}=0.999 \\
\widetilde{R}_{i i}=0.95 \\
\mu^{\alpha^{\gamma}}=x x x \\
\mu^{\beta^{\delta}}=x x x \\
\mu^{\theta^{\tau}}=x x x\end{array}$ & $\begin{array}{l}\text { Other }^{\gamma}=2.31 \\
\text { Other }^{\delta}=-1.142 \\
\text { Other }^{\tau}=27.064 \\
g_{\alpha^{\gamma}, i, 1}=-0.75 \\
g_{\alpha^{\gamma}, i i, 1}=-1.04 \\
g_{\beta^{\delta}, i, 1}=-0.76 \\
g_{\beta^{\delta}, i i, 1}=-1.04 \\
g_{\theta^{\tau}, i, 1}=-0.75 \\
g_{\theta^{\tau}, i i, 1}=-1.04 \\
u_{i, 1}=3.64 \\
u_{i i, 1}=3.6 \\
M=6.928\end{array}$ & $\begin{array}{l}a_{\alpha^{\gamma}, 1}=-3.85 \\
a_{\beta^{\delta}, 1}=-3.35 \\
a_{\theta^{\tau}, 1}=-2.08 \\
z_{\gamma, 1}=1.56 \\
z_{\delta, 1}=2.53 \\
z_{\tau, 1}=3.3 \\
c_{i}^{\gamma}=0.214 \\
c_{i i}^{\gamma}=0.129 \\
c_{i}^{\delta}=0.159 \\
c_{i i}^{\delta}=0.351 \\
c_{i}^{\tau}=0.024 \\
c_{i i}^{\tau}=0.042\end{array}$ \\
\hline Calibrated & $\begin{array}{l}\rho=0.04 \\
\bar{m}^{\gamma}=x x x \\
\bar{m}^{\delta}=x x x \\
\bar{m}^{\tau}=x x x \\
d_{\gamma}^{\phi}=x x x\end{array}$ & $\begin{array}{l}d_{\delta}^{\phi}=x x x \\
d_{\tau}^{\phi}=x x x \\
\mu^{\gamma}=x x x \\
d^{\delta}=x x x \\
\mu^{\tau}=x x x\end{array}$ & $\begin{array}{l}v_{i \gamma}^{\alpha^{\gamma}}=x x x \\
v_{i \delta}^{\beta^{\delta}}=x x x \\
v_{i \tau}^{\theta^{\gamma}}=x x x \\
\mathrm{GDP}_{i}=104.3\end{array}$ & $\begin{array}{l}e_{0}^{\gamma}=x x x \\
e_{0}^{\delta}=x x x \\
e_{0}^{\tau}=x x x \\
a_{h^{b}, 2}=1.41, \forall h \in H^{b} \\
a_{h^{b}, 3}=-0.68, \forall h \in H^{b}\end{array}$ & $\begin{array}{l}\bar{\omega}=1 \\
\omega(\widetilde{\omega})=0.2 \\
A^{\gamma}=x x x \\
A^{\delta}=x x x \\
A^{\tau}=x x x\end{array}$ \\
\hline $\begin{array}{l}\text { Arbitrarily } \\
\text { selected }\end{array}$ & $\begin{array}{l}v_{i}^{\gamma}=0.999 \\
v_{i i}^{\gamma}=0.95 \\
v_{i}^{\delta}=0.999\end{array}$ & $\begin{array}{l}v_{i i}^{\delta}=0.955 \\
v_{i}^{\tau}=0.999 \\
v_{i i}^{\tau}=0.95\end{array}$ & $\begin{aligned} v_{i i \gamma}^{\alpha^{\gamma}} & =0.9 \\
v_{i i \delta}^{\beta^{\delta}} & =0.9 \\
v_{i i \tau}^{\theta^{\tau}} & =0.9 \\
\operatorname{GDP}_{i i} & =100.2\end{aligned}$ & $\begin{array}{l}\lambda_{k s}^{b}=0.1, \forall b \in B, s \in S \\
\lambda_{i}^{b}=0.9, \forall b \in B \\
\lambda_{i i}^{b}=1.1, \forall b \in B \\
u_{s, 2}=0.1, \forall s \in S \\
z_{b, 2}=0.19, \forall b \in B \\
z_{b, 3}=0.5, \forall b \in B \\
z_{b, 4}=-0.1, \forall b \in B \\
g_{h, i, 2}=0.05, \forall h \in H^{b} \\
g_{h, i i, 2}=0.05, \forall h \in H^{b} \\
g_{h, i, 3}=0.05, \forall h \in H^{b} \\
g_{h, i i, 3}=0.1, \forall h \in H^{b}\end{array}$ & $\begin{array}{l}\bar{k}^{\gamma}=0.11 \\
\bar{k}^{\delta}=0.16 \\
\bar{k}^{\tau}=0.13 \\
r^{A}=0.045 \\
p=0.95\end{array}$ \\
\hline
\end{tabular}




\section{Comparative Static Analysis: Stress Testing UK Banks}

In this section we show how the model can be used as a risk assessment tool for UK banks. Given that the initial equilibrium has been found, we conduct a series of comparative statics by perturbing each of the variables which are exogenous in the model and studying how the initial equilibrium changes. ${ }^{15}$ Tables A1 in the Appendix reports the directional responses of all endogenous variables in the model given that we increase the values of the variables listed in the first column one at a time. Recall that these comparative statics are based on the baseline specification, which assumes that the Central Bank's monetary policy instrument is its base money. In what follows, we also conduct an alternative set of comparative statics whereby the Central Bank is assumed to set the interbank rate as its instrument and let the interbank rate adjusts endogenously. ${ }^{16}$ Table A2 in the Appendix reports the results of this alternative set of comparative statics in an analogous format to table A1.

\subsection{An expansionary monetary policy}

We first analyse the case when the Bank of England engages in an expansionary monetary policy. As expected, we found that the result is exactly the same regardless of whether the Bank uses its base money or the interbank rate as its monetary policy instrument (i.e. the Bank increases its base money and allows the interbank rate to be determined endogenously, produces the same result as the case when the Bank decreases the interbank rate and lets its base money adjust endogenously). We summarise the percentage changes in the values of certain key variables in response to an increase in the Bank's base money from 69.28 to 71.28 trillion pounds (approximately 2.9\%) in table II. As can be seen from the table, the interbank rate decreases by $0.8 \%$. Given a lower rate of return on interbank market investment, other things constant, bank $\delta$ invests less in this market (recall that bank $\delta$ is the net lender in this market). It demands less funds from the deposit market and it increases its loan supply to its nature-selected customer, Mr. $\beta$. This portfolio adjustment of bank $\delta$ produces a negative pressure on both its deposit and lending rates. Unlike bank $\delta$, banks $\gamma$ and $\tau$ are the net borrowers in the interbank market. Thus they respond to a lower cost of interbank borrowing by reducing their demand for deposits, borrowing more from the interbank market, and lending more to their nature-selected customers, Mr. $\alpha$ and $\theta$, respectively. This, in turn, causes a negative pressure on these two banks' deposit and lending rates.

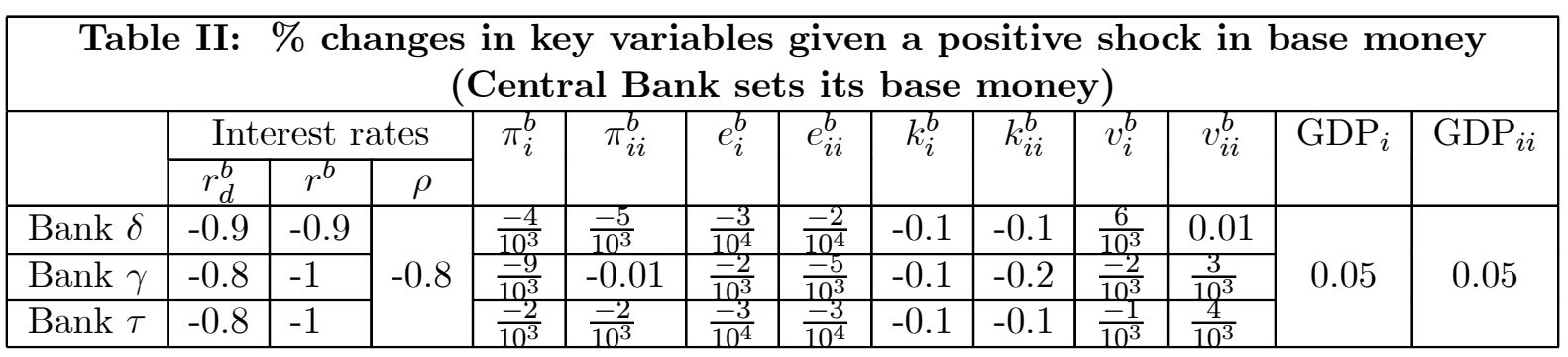

All banks rationally anticipate that their greater credit extension would increase the overall supply of credit in the economy, thus causing the probability of household default to decline.

\footnotetext{
${ }^{15}$ The calculation is carried out using a version of Newton's method in Mathematica.

${ }^{16}$ More specifically, the interbank rate becomes an exogenous parameter in the model under this alternative specification.
} 
This is because greater aggregate credit supply not only directly increases households' liquidity but also increases their income in both states of the subsequent period. As can be seen from table II, GDP increases by $0.05 \%$ in both states. Thus, the expected rate of return from extending loans increases for all banks, implying that their willingness to supply more credit rises even further.

Given higher expected GDP in both states, every household borrower (i.e. Mr. $\alpha, \beta$, and $\theta$ ) demands more loans, imposing a positive pressure on the lending rates offered by their respective nature-selected banks. However, this 'crowding-out' effect is dominated by the corresponding negative pressure from greater credit supply by all banks. Thus, we observe that their lending rates decline $(0.9 \%$ for bank $\delta$, and $1 \%$ for banks $\gamma$ and $\tau)$. We also find that the deposit rates offered by all banks decrease (i.e. $0.9 \%$ for bank $\delta$ and $0.8 \%$ for banks $\gamma$ and $\tau)$. This is not only because all banks demand less funds from the deposit markets but also because Mr. $\phi$ responds to higher expected GDP by supplying more deposits to every bank.

Banks in our model choose their optimal expected level of profitability by equating the derived marginal benefit with the corresponding marginal cost. On the one hand, higher profitability not only directly increases their utility but also raises their capital to asset ratios, allowing them to suffer less capital violation penalties. This latter source of marginal benefit is lower the higher the value of banks' risk-weighted assets. ${ }^{17}$ On the other hand, in order to achieve higher profitability, other things constant, they take more risk and therefore suffer higher cost in the form of higher expected default penalties. ${ }^{18}$ In this comparative static exercise, since the default probability of all household borrowers decreases in both states, the corresponding values of every bank's risk-weighted assets increase. This leads all banks to revise the trade off between the relative marginal benefit and cost in such as way that they are willing to achieve a marginally lower level of profitability in both states, compared with the corresponding initial equilibrium value, in pursuit of suffering less default penalties. ${ }^{19}$ Consequently, their capital declines slightly in both states compared with the initial equilibrium. This, together with the fact that the values of their risk-weighted assets increase, causes all banks to suffer greater capital violation penalties.

Given that banks operate under a perfectly competitive environment, they treat all interest rates and the households' default probability as given when making their optimal decisions. However, in response to shocks, these variables have to adjust endogenously to satisfy market clearing conditions, where the direction and extent of the adjustment depend on how banks and households adjust their portfolios. This 'portfolio reallocation' effect produces pressures on banks' profitability and their willingness to take risk. ${ }^{20}$ As for bank $\delta$ in both states and banks $\gamma$ and $\tau$ in the bad state, this portfolio reallocation effect is relatively weak, causing

\footnotetext{
${ }^{17}$ For example, if the profit of a bank increases by 1 dollar, given that its risk-weighted asset is 100 dollar, its capital to asset ratio would increase by $\frac{1}{100}$. However, if the value of the risk-weighted assets is 1000 dollar, the bank's capital to asset ratio would increase by much less, i.e. by $\frac{1}{1000}$.

${ }^{18}$ Recall that we interpret a bank's continuous default rate as isomorphic to the probability that the bank will shut down, and therefore, at least in the very short run, completely default on its obligations. Thus, when banks choose higher default rates, this implies that it adopts a riskier position.

${ }^{19}$ More precisely, higher risk-weighted assets in both states for all banks cause their marginal benefit of achieving higher profitability in terms of suffering less capital violation penalties to decrease. Given that the marginal benefit of achieving higher profitability is now lower than the corresponding marginal cost, they reduce their optimal desired level of profits.

${ }^{20}$ For example, a bank may respond to a positive shock by supplying more loans, thereby imposing a negative pressure on the lending rate. Similarly, the shock may cause household borrowers to demand more loans from such a bank, causing a positive crowding-out pressure on the lending rate. The relative strength of the pressures caused by the bank's and the borrower's portfolio adjustment depends in general on the relative elasticities of demand and supply in such a market.
} 
them to simply adopt a more conservative position in response to their lower targeted level of profitability. However, for banks $\gamma$ and $\tau$ in the good state, the portfolio reallocation effect produces a relatively strong negative pressure on their profitability so that they end up adopting a slightly riskier position in order to achieve their targeted level of profits.

\subsection{A positive deposit supply shock to bank $\delta$ in the initial period}

We next turn to the scenario where there is a positive deposit supply shock to bank $\delta$ in the initial period. In particular, we increase the $(\log )$ autonomous deposit supply of Mr. $\phi$ with bank $\delta\left(z_{\delta, 1}\right)$ by approximately $0.8 \%$. We first assume that the Bank fixes base money as its monetary policy instrument, allowing the interbank rate to be determined endogenously. We report the percentage changes of certain key variables in response to the shock in table III. Not surprisingly, the results are almost qualitatively identical to that of a change in the Bank's injection of funds, since both represent a change in the overall broad money supply. The difference is that here we assume that the shock is concentrated in bank $\delta$.

\begin{tabular}{|c|c|c|c|c|c|c|c|c|c|c|c|c|c|}
\hline \multicolumn{14}{|c|}{$\begin{array}{c}\text { Table III: \% changes in key variables given a positive deposit supply } \\
\text { shock on bank } \delta \text { (Central Bank sets base money) }\end{array}$} \\
\hline & \multicolumn{3}{|c|}{ Interest rates } & \multirow[t]{2}{*}{$\pi_{i}^{b}$} & \multirow[t]{2}{*}{$\pi_{i i}^{b}$} & \multirow[t]{2}{*}{$e_{i}^{b}$} & \multirow[t]{2}{*}{$e_{i i}^{b}$} & \multirow[t]{2}{*}{$k_{i}^{b}$} & \multirow[t]{2}{*}{$k_{i i}^{b}$} & \multirow[t]{2}{*}{$v_{i}^{b}$} & \multirow[t]{2}{*}{$v_{i}^{b}$} & \multirow[t]{2}{*}{$\mathrm{GDP}_{i}$} & \multirow[t]{2}{*}{$\mathrm{GDP}_{i i}$} \\
\hline & $r_{d}^{b}$ & $r^{b}$ & $\rho$ & & & & & & & & & & \\
\hline Bank $\delta$ & -2.7 & -2.9 & \multirow{3}{*}{-2.3} & -0.03 & -0.04 & $\frac{-3}{10^{3}}$ & $\frac{-2}{10^{3}}$ & -0.8 & -0.9 & 0.03 & 0.03 & \multirow{3}{*}{0.16} & \multirow{3}{*}{0.16} \\
\hline Bank $\gamma$ & -2.3 & -3.2 & & -0.03 & -0.04 & $\frac{-5}{10^{3}}$ & -0.02 & -0.4 & -0.5 & $\frac{-6}{10^{3}}$ & $\frac{9}{10^{3}}$ & & \\
\hline Bank $\tau$ & -2.3 & -3.1 & & $\frac{-5}{10^{3}}$ & $\frac{-6}{10^{3}}$ & $\frac{-9}{10^{4}}$ & $\frac{-9}{10^{4}}$ & -0.4 & -0.4 & $\frac{-3}{10^{3}}$ & 0.01 & & \\
\hline
\end{tabular}

Major differences arise, however, when we analyse the effects of the shock in the context whereby the Bank fixes the interbank rate as its monetary policy instrument. Key results are summarised in table IV. In the previous case, even though the effect of the shock is initially concentrated in bank $\delta$, we observe that the other two banks also benefit from increased overall liquidity through their interactions in the interbank market. In particular, a positive deposit supply shock in bank $\delta$ causes the bank to supply more liquidity in the interbank market. Such higher liquidity is then passed on to banks $\gamma$ and $\tau$ in the form of a lower cost of interbank borrowing. However, in this case, the Bank's intervention to maintain the interbank rate at its original level precisely shuts down this interbank rate channel, causing the dominant channel of contagion to become the one which operates via changes in the household sector's default probability in the loan market instead. The chain of contagion of this 'consumer loan default' channel begins with bank $\delta$ 's decision to supply more credit. This in turn causes the overall credit supply in the economy to increase. This implies that every household benefits directly from greater liquidity as well as from higher income (GDP) in both states $i$ and $i i$ of the subsequent period. Thus, the default probability of every household in the consumer loan market decreases, causing the expected rate of return from extending more loans to increase not only for bank $\delta$ but also for banks $\gamma$ and $\tau$. Consequently, their respective lending rates fall. Since the cost of interbank borrowing is fixed regardless of the amount demanded, the two banks finance their greater credit extension by borrowing more from the interbank market. 


\begin{tabular}{|c|c|c|c|c|c|c|c|c|c|c|c|c|c|}
\hline \multicolumn{14}{|c|}{$\begin{array}{c}\text { Table IV: \% changes in key variables given a positive deposit supply shock } \\
\text { on bank } \delta \text { (Central Bank sets the interbank rate) }\end{array}$} \\
\hline & Inte & rest ra & & $\pi_{i}^{b}$ & $\pi_{i i}^{b}$ & $e_{i}^{b}$ & $e_{i i}^{b}$ & $k_{i}^{b}$ & $k_{i i}^{b}$ & $v_{i}^{b}$ & $v_{i i}^{b}$ & $\mathrm{GDP}_{i}$ & $\mathrm{GDP}_{i i}$ \\
\hline & $r_{d}^{b}$ & $r^{b}$ & $\rho$ & & & & & & & & & & \\
\hline Bank $\delta$ & $\frac{4}{10^{3}}$ & -0.01 & \multirow{3}{*}{0} & -0.02 & -0.02 & $\frac{-2}{10^{3}}$ & $\frac{-1}{10^{3}}$ & -0.5 & -0.5 & $\frac{8}{10^{3}}$ & $\frac{-3}{10^{3}}$ & \multirow{3}{*}{$\frac{3}{10^{4}}$} & \multirow{3}{*}{$\frac{3}{10^{4}}$} \\
\hline Bank $\gamma$ & 0 & $\frac{-3}{10^{3}}$ & & 0 & 0 & 0 & 0 & $\frac{-8}{10^{4}}$ & $\frac{-9}{10^{4}}$ & 0 & 0 & & \\
\hline Bank $\tau$ & 0 & $\frac{-3}{10^{3}}$ & & 0 & 0 & 0 & 0 & $\frac{-7}{10^{4}}$ & $\frac{-8}{10^{4}}$ & 0 & 0 & & \\
\hline
\end{tabular}

As can be seen clearly by comparing the results presented in tables III and IV, the contagion effects when the Bank's monetary instrument is the interbank rate are much weaker than those observed when the Bank fixes its base money. This is because fixing the interbank rate not only directly shuts down the interbank rate contagion channel but also weakens the extent of contagion effects which operate through the consumer loan default channel. As mentioned, the contagion effects which operate via the latter channel arise from bank $\delta$ 's decision to extend more credit. However, the Bank's intervention to fix the interbank rate implicitly increases the attractiveness of the interbank investment for bank $\delta$ since its rate of return does not diminish as it invests more. Thus, even though we observe that bank $\delta$ increases its credit extension when the Bank fixes the interbank rate, the extent of such increase is not as strong compared to the case when the rate is allowed to adjust endogenously. Put differently, the money supply multiplier is larger when the Bank does not target interest rates since besides their direct effect due to increased deposits, a second-order effect from allowing the interbank rate to change enhances credit supply of the entire banking sector.

\subsection{A positive bank capital shock to bank $\delta$ in the initial period}

In this comparative static exercise, we increase the capital endowment of bank $\delta$ in the initial period by approximately $5.6 \%$. As before, we first consider the case when the Bank sets its base money as its instrument. The percentage changes in the values of certain key variables in response to such shock is summarised in table $\mathrm{V}$. We observe that the directional responses of most of the variables are the same as the case when we assume that there is a positive deposit supply shock to bank $\delta$. This is because these two shocks both result in more available funds for bank $\delta$ to invest. However, the exception is the response of bank $\delta$ 's capital, and capital to asset ratios, in the second period. Unlike the case of the positive deposit supply shock, here we observe that bank $\delta$ 's capital position and its capital to adequacy ratios improve in both states of the world. The reason for this lies in the fact that a positive endowment shock imposes a direct positive effect on the capital of bank $\delta$ in the second period, thus reducing its capital requirements' violation penalty.

\begin{tabular}{|c|c|c|c|c|c|c|c|c|c|c|c|c|c|}
\hline \multicolumn{14}{|c|}{$\begin{array}{c}\text { Table V: \% changes in key variables given a positive shock on } \\
\text { bank } \delta \text { 's capital at } t=1 \text { (Central Bank sets base money) }\end{array}$} \\
\hline & \multicolumn{3}{|c|}{ Interest rates } & \multirow[t]{2}{*}{$\pi_{i}^{b}$} & \multirow[t]{2}{*}{$\pi_{i}^{b}$} & \multirow[t]{2}{*}{$e_{i}^{b}$} & \multirow[t]{2}{*}{$\overline{e_{i i}^{b}}$} & \multirow[t]{2}{*}{$k_{i}^{b}$} & \multirow[t]{2}{*}{$k_{i i}^{b}$} & \multirow[t]{2}{*}{$v_{i}^{b}$} & \multirow[t]{2}{*}{$v_{i i}^{b}$} & \multirow{2}{*}{$\overline{\mathrm{GDP}_{i}}$} & \multirow{2}{*}{$\mathrm{GDP}_{i i}$} \\
\hline & $r_{d}^{b}$ & $r^{b}$ & $\rho$ & & & & & & & & & & \\
\hline Bank $\delta$ & -0.9 & -0.9 & \multirow{3}{*}{-0.8} & -0.01 & $\begin{array}{l}-0.01 \\
\end{array}$ & 5.1 & 5.8 & 4.9 & 5.5 & 0.03 & $\frac{5}{10^{3}}$ & \multirow{3}{*}{0.05} & \multirow{3}{*}{0.05} \\
\hline Bank $\gamma$ & -0.8 & -1 & & $\frac{-9}{10^{3}}$ & -0.01 & $\frac{-2}{10^{3}}$ & $\frac{-5}{10^{3}}$ & -0.1 & -0.2 & $\frac{-2}{10^{3}}$ & $\frac{3}{10^{3}}$ & & \\
\hline Bank $\tau$ & -0.8 & -1 & & $\frac{-2}{10^{3}}$ & $\frac{-2}{10^{3}}$ & $\frac{-3}{10^{4}}$ & $\frac{-3}{10^{4}}$ & -0.1 & -0.1 & $\frac{-1}{10^{3}}$ & $\frac{4}{10^{3}}$ & & \\
\hline
\end{tabular}


We now turn to analyse the effects of the same shock but this time under the assumption that the Bank fixes the interbank rate. Key results are reported in table VI. As in the case when there is a positive deposit supply shock to bank $\delta$ in state $i i$, we found in this case that the main contagion effects operate via the consumer loan default channel. However, the major difference is that here the effects of liquidity injection in bank $\delta$ produces negative contagion effects onto the rest of the banks in the banking sector. Recall that the Bank's sterilisation policy in the interbank market increases the relative attractiveness of interbank investment, implying that bank $\delta$ responds to higher capital by increasing its investment in the interbank market. Unlike the results found in section 1.2, however, the extent of such increase is so large that bank $\delta$ has to switch part of its investment away from the loan market. This in turn puts a downward pressure on the overall credit supply in the economy, aggravating the probability of default in the consumer loan markets. This negative contagion effect depresses the other two banks' expected return on their credit extension. Thus, they extend less credit, causing the aggregate output to fall in both states. This in turn worsens the severity of credit crunch in the economic system even further. Moreover, unlike before, we observe that banks $\gamma$ and $\tau$ now violate 'less' capital adequacy requirements and therefore suffer less capital violation penalties. This is because a higher default probability of every household causes the values of banks $\gamma$ 's and $\tau$ 's risk-weighted assets to decrease. In sum, we see that emergency liquidity assistance in the form of bank capital injection, when implemented under interest rate targeting regime, may engender adverse effects to financial stability. Banks may radically restructure their portfolios in a way that depresses credit extension in the loan markets.

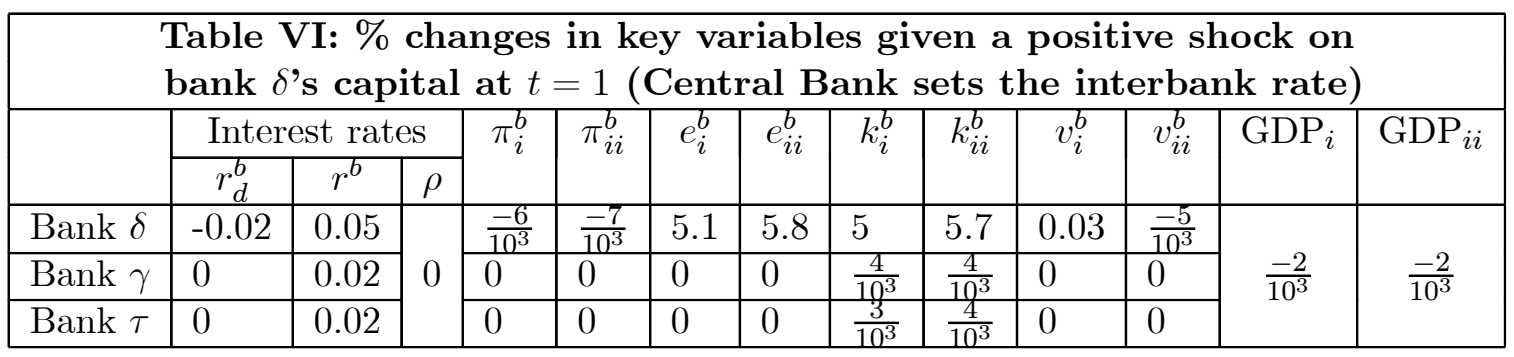

One of the key implications from our results presented thus far is that, as far as financial stability is concerned, there is no clear-cut answer as to whether a Central Bank should set the interbank rate or base money as its monetary policy instrument. Although all the contagion effects which operate through the interbank rate channel are completely sterilised away when the Central Bank's instrument is the interbank rate, such a sterilisation policy may mitigate the extent of contagion effects which operate via other channels of contagion. As the results in this section show, the direction of contagion effects can even be reversed, thereby producing negative rather than positive contagion effects to the rest of the economic system. Disentangling the issue is clearly beyond the scope of this paper. Since our main objective here is to study financial contagion and banks' inter-linkages, we have chosen to focus our analysis in the remainder of this paper on our baseline specification (i.e. the Bank's monetary policy instrument is base money). This allows all contagion channels to operate actively in equilibrium.

\subsection{An increase in default penalties imposed on all banks in the bad state}

We now turn to analyse the case where the regulator engages in a restrictive regulatory policy by increasing the default penalties imposed on all banks in the bad state from 1.1 to 1.12 
(approximately 1.8\%). This implies that adopting a riskier position in the bad state is more costly for all banks since by doing so they have to suffer greater default penalties in this particular state. Thus, as reported in table VII, all banks optimally choose a significantly lower desired level of profitability in the bad state, allowing them to adopt a much more conservative position and therefore to mitigate the extent of default penalties that they have to face in this particular state. Moreover, bank $\delta$ increases its investment in the interbank market which is relatively 'safer' in the bad state. ${ }^{21}$ In doing so, it borrows more from the deposit market, and invests less in the loan market. This portfolio adjustment of bank $\delta$ imposes a negative pressure on the interbank rate and produces a positive pressure on its lending and deposit rates. In response, Mr. $\phi$ supplies more deposits with bank $\delta$ and less with the other two banks.

\begin{tabular}{|c|c|c|c|c|c|c|c|c|c|c|c|c|c|}
\hline \multicolumn{14}{|c|}{$\begin{array}{l}\text { Table VII: \% changes in key variables given a rise in default penalty for } \\
\text { all banks in state ii (Central Bank sets base money) }\end{array}$} \\
\hline & \multicolumn{3}{|c|}{ Interest rates } & \multirow[t]{2}{*}{$\pi_{i}^{b}$} & \multirow[t]{2}{*}{$\pi_{i i}^{b}$} & \multirow[t]{2}{*}{$e_{i}^{b}$} & \multirow[t]{2}{*}{$e_{i i}^{b}$} & \multirow[t]{2}{*}{$k_{i}^{b}$} & \multirow[t]{2}{*}{$k_{i i}^{b}$} & \multirow[t]{2}{*}{$v_{i}^{b}$} & \multirow[t]{2}{*}{$v_{i i}^{b}$} & \multirow[t]{2}{*}{$\mathrm{GDP}_{i}$} & \multirow[t]{2}{*}{$\mathrm{GDP}_{i i}$} \\
\hline & $r_{d}^{b}$ & $r^{b}$ & $\rho$ & & & & & & & & & & \\
\hline Bank $\delta$ & 0.3 & 0.3 & \multirow{3}{*}{-0.4} & $\frac{3}{10^{4}}$ & $\begin{array}{l}-20.9 \\
\end{array}$ & $\frac{3}{10^{5}}$ & $\begin{array}{l}-0.8 \\
\end{array}$ & $\frac{9}{10^{3}}$ & -0.8 & $\frac{3}{10^{3}}$ & 0.1 & \multirow{3}{*}{$\frac{-3}{10^{3}}$} & \multirow{3}{*}{$\frac{-3}{10^{3}}$} \\
\hline Bank $\gamma$ & -0.4 & -0.08 & & $\frac{1}{10^{4}}$ & -21.6 & $\frac{2}{10^{5}}$ & -9.4 & $\frac{2}{10^{3}}$ & -9.4 & $\frac{8}{10^{3}}$ & 0.6 & & \\
\hline Bank $\tau$ & -0.4 & -0.08 & & $\frac{2}{10^{5}}$ & -20.2 & $\frac{3}{10^{6}}$ & $\begin{array}{l}-3.3 \\
\end{array}$ & $\frac{2}{10^{3}}$ & -3.3 & $\frac{\frac{y}{1}}{10^{3}}$ & 0.3 & & \\
\hline
\end{tabular}

Unlike bank $\delta$, banks $\gamma$ 's and $\tau$ 's initial positions in the interbank market are net borrowers. Thus, even though interbank investment is now relatively safer, switching its 'net' position in such market would result in a relatively more severe negative portfolio reallocation effect on these banks' overall payoff. Anticipating this, they 'gamble to resurrect' by extending more loans, expecting that such an action would increase their profitability in the good state, which is not subject to higher default penalties, and therefore to reduce the extent of the decline in their overall payoff which is due mainly to the significant fall in their profitability in the bad state. This causes their lending rates to decrease both by $0.08 \%$. Given a lower interbank rate, they also adjust their portfolios by switching away from the deposit market and borrowing more from the interbank market, causing their deposit rates to decrease by $0.4 \%$.

We observe that the extent of decrease in bank $\delta$ 's credit extension is larger than the extent of increase in banks $\gamma$ 's and $\tau$ 's credit supply combined, causing the overall supply of credit in the economy to fall. This directly decreases households' liquidity, which in turn imposes a downward pressure on the probability that households will repay their loan obligations in full. This pressure is further exacerbated since lower aggregate credit supply depresses GDP in both states of the second period (i.e. by $0.003 \%$ in both states), causing the corresponding income of every household to fall.

As mentioned, because of the direct first-order effect of the initial shock (i.e. higher default penalty in state $i i$ ), all banks are willing to obtain lower profitability in the bad state, compared with the corresponding initial equilibrium level, and therefore to adopt a more conservative position in the bad state, causing their corresponding profitability and capital to decrease so much that they suffer more capital violation penalties in this particular state. In state $i$, although households' default probability is higher, the resulting positive pressure on all

\footnotetext{
${ }^{21}$ More specifically, the probability with which banks $(\gamma, \tau)$ choose to default completely on their interbank obligations is less than the corresponding probability of $\mathrm{Mr} . \beta$ on his loans.
} 
banks' risk-weighted assets is relatively weak and therefore outweighed by the corresponding negative portfolio adjustment effect, causing the values of their risk-weighted assets in this particular state to decrease. This changing condition alters the trade off between the benefit derived from higher profitability and the corresponding cost in terms of suffering more default penalties in such a way that it favours the former. Thus, all banks optimally choose to target a slightly higher level of profitability in the good state, causing the corresponding value of their capital to increase marginally. Even though the targeted level of profits is higher, owing to the relatively strong and positive portfolio reallocation effect, all banks can adopt a slightly more conservative position in the good state. Finally, since the values of risk-weighted assets decrease for all banks in the good state and that the corresponding values of their capital increase, they suffer slightly less capital violation penalties in this particular state.

\subsection{An increase in capital violation penalties for all banks in the bad state}

We next turn to another restrictive regulatory policy. Let the regulator increase the capital violation penalties for all banks in the bad state from 0.1 to 0.12 (approximately 20\%). We summarise the percentage changes of some of the key variables in response to such shock in table VIII. ${ }^{22}$

\begin{tabular}{|c|c|c|c|c|c|c|c|c|c|c|c|c|c|}
\hline \multicolumn{14}{|c|}{$\begin{array}{l}\text { Table VIII: \% changes in key variables given a rise in CAR penalty for } \\
\text { all banks in state } i i \text { (Central Bank sets base money) }\end{array}$} \\
\hline & Inter & st re & & $\pi_{i}^{b}$ & $\overline{\pi_{i i}^{b}}$ & $e_{i}^{b}$ & $e_{i i}^{b}$ & $k_{i}^{b}$ & $k_{i i}^{b}$ & $v_{i}^{b}$ & $v_{i i}^{b}$ & $\mathrm{GDP}_{i}$ & $\mathrm{GDP}_{i i}$ \\
\hline & $r_{d}^{b}$ & $r^{b}$ & $\rho$ & & & & & & & & & & \\
\hline Bank $\delta$ & -0.02 & $\frac{6}{10^{3}}$ & \multirow{3}{*}{$\frac{-6}{10^{3}}$} & $\frac{1}{10^{5}}$ & 0.9 & 0 & 0.04 & $\frac{2}{10^{4}}$ & 0.04 & $\frac{6}{10^{4}}$ & $\frac{-4}{10^{3}}$ & \multirow{3}{*}{$\frac{-8}{10^{4}}$} & \multirow{3}{*}{$\frac{-8}{10^{4}}$} \\
\hline Bank $\gamma$ & $\frac{-6}{10^{3}}$ & $\frac{5}{10^{3}}$ & & $\frac{2}{10^{5}}$ & 1.6 & 0 & 0.7 & $\frac{4}{10^{4}}$ & 0.7 & $\frac{5}{10^{4}}$ & -0.05 & & \\
\hline Bank $\tau$ & $\frac{-6}{10^{3}}$ & $\frac{-1}{10^{3}}$ & & 0 & 0.2 & $\overline{0}$ & 0.04 & $\frac{1}{10^{4}}$ & 0.04 & $\frac{1}{10^{4}}$ & $\frac{-4}{10^{3}}$ & & \\
\hline
\end{tabular}

Since violating capital requirement in state $i i$ is now more costly for all banks, in response, they engage in the following actions in an attempt to increase the values of their capital to asset ratios in the bad state. First, they choose to increase their optimal profitability level in this particular state by adopting a riskier position. The higher profitability, other things constant, improves their capital position in the bad state, allowing them ultimately to suffer fewer capital violation penalties. Second, banks $\gamma$ and $\delta$ adjust their portfolios such that the size of their risk-weighted assets in the bad state decreases, thereby alleviating the extent of their capital requirements' violation even further. For bank $\gamma$, it reduces its overall investment by demanding less funds, both from the deposit and interbank markets, and invests less in the loan market. This causes both the interbank rate and its deposit rate to decrease and its lending rate to increase. Consequently, Mr. $\phi$ supplies less deposits with bank $\gamma$ and Mr. $\alpha$

\footnotetext{
${ }^{22}$ As can be seen from the results reported in tables VII and VIII, the effects of an increase in default penalty are much stronger than the case when we increase the capital requirements violation penalty by a comparable magnitude. This is owing to our choice of parameterisation which assumes that banks care relatively more about them being penalised from defaulting on their financial obligations, rather than violating more their capital requirements. This is a reasonable assumption since banks in our model compare their actual level of capital with their self-imposed ideal capital holding, not the (Pillar 1) minimum capital requirements. Thus, as mentioned earlier, the cost of violating capital requirements in our model largely represents a non-pecuniary loss of comfort and reputation. Such cost should be of less concern to the banks as contrasted with the cost that they bear from breaching their financial obligations.
} 
demands less funds from bank $\gamma$. Bank $\delta$ also demands less funds from the deposit market, causing its deposit rate to fall and Mr. $\phi$ to supply less deposits with bank $\delta$. Moreover, it reduces its investment both in the loan and interbank markets. The extent of decline in bank $\delta$ 's interbank investment is further aggravated since the interbank rate is now lower. Because bank $\delta$ 's action produces an upward pressure on its lending rate, Mr. $\beta$ demands less consumer loans.

Even though a higher capital violation penalty in state $i i$ produces an upward pressure on the cost of extending more credit for bank $\tau$, such a pressure is marginally outweighed by the negative pressure arising from a cheaper cost of interbank borrowing. Thus, bank $\tau$ borrows less from the deposit market, switches to borrow more from the interbank market, and extends slightly more loans to Mr. $\theta$. Thus, both its deposit and lending rates decrease by $0.006 \%$ and $0.001 \%$, respectively.

Because the extent of decrease in credit extension by banks $\gamma$ and $\delta$ over-compensates the extent of increase in the credit supply of bank $\tau$, the aggregate supply of credit in the economy decreases. This causes GDP to decline in both states (i.e. by $0.0008 \%$ in both states), which in turn results in a higher default probability of every household.

\subsection{A positive shock in GDP in the bad state}

Our final comparative static exercise studies the effect of a positive shock in the autonomous component of GDP in the bad state. In particular, we increase the value of $u_{1}$ by $0.6 \%{ }^{23}$ Table IX summarises certain key results.

\begin{tabular}{|c|c|c|c|c|c|c|c|c|c|c|c|c|c|}
\hline \multicolumn{14}{|c|}{$\begin{array}{c}\text { Table IX: \% changes in key variables given a rise GDP in the bad state } \\
\text { (Central Bank sets base money) }\end{array}$} \\
\hline & \multicolumn{3}{|c|}{ Interest rates } & \multirow[t]{2}{*}{$\pi_{i}^{b}$} & \multirow[t]{2}{*}{$\pi_{i i}^{b}$} & \multirow[t]{2}{*}{$e_{i}^{b}$} & \multirow[t]{2}{*}{$e_{i i}^{b}$} & \multirow[t]{2}{*}{$k_{i}^{b}$} & \multirow[t]{2}{*}{$k_{i i}^{b}$} & \multirow[t]{2}{*}{$v_{i}^{b}$} & \multirow[t]{2}{*}{$v_{i i}^{b}$} & \multirow[t]{2}{*}{$\mathrm{GDP}_{i}$} & \multirow[t]{2}{*}{$\mathrm{GDP}_{i i}$} \\
\hline & $r_{d}^{b}$ & $r^{b}$ & 0 & & & & & & & & & & \\
\hline Bank $\delta$ & 2.4 & 1.1 & \multirow{3}{*}{1} & $\frac{-4}{10^{3}}$ & $\frac{-9}{10^{3}}$ & $\frac{-4}{10^{3}}$ & $\frac{-4}{104}$ & -0.1 & -0.2 & -0.02 & 0.06 & \multirow{3}{*}{0.01} & \multirow{3}{*}{2.03} \\
\hline Bank $\gamma$ & 2 & 1.1 & & $\frac{-7}{-13}$ & -0.02 & $\frac{-1}{-13}$ & $\frac{-7}{-7}$ & -0.1 & -0.2 & $\frac{1}{10^{3}}$ & $\frac{1}{10^{3}}$ & & \\
\hline$\overline{B a n k} \tau$ & 2 & 1.1 & & $\frac{-1}{10^{3}}$ & $\frac{-2}{10^{3}}$ & $\frac{-2}{10^{3}}$ & $\frac{-4}{11}$ & -0.1 & -0.2 & $\frac{-1}{10^{3}}$ & 0.1 & & \\
\hline
\end{tabular}

The shock directly increases the expected aggregate output in the second period. This simultaneously raises all individual borrowers' demand for loans, and the probability that they will repay their loans in full, as well as increases Mr. $\phi$ 's supply of deposits with every bank. Given a higher loan demand by Mr. $\alpha$ and $\theta$, the lending rates offered by their respective natureselected banks $(\gamma$ and $\tau$ ) increase by $1.1 \%$. Moreover, a decrease in the default probability of Mr. $\alpha$ and $\theta$ further raises the expected rates of return on credit extension for banks $\gamma$ and $\tau$. Thus, these banks supply more credit, and demand more funds from both the deposit and interbank markets. Even though Mr. $\phi$ 's decision to deposit more with these banks imposes a negative pressure on banks $\gamma$ 's and $\tau$ 's deposit rates, such a pressure is relatively weak when compared to the positive effect from these banks' greater demand for deposits. Thus, we observe that the interbank rate and the deposit rates offered by the two banks increase.

For the same reason as banks $\gamma$ and $\tau$, bank $\delta$ supplies more loans to Mr. $\beta$. Unlike the other two banks, however, bank $\delta$ is the net lender in the interbank market. So, it responds to a higher interbank rate by investing more in the interbank market. To finance its greater

\footnotetext{
${ }^{23}$ This is tantamount to an increase in the autonomous GDP in the bad state by $2.02 \%$.
} 
investment, bank $\delta$ demands more funds from the deposit market, pushing up its deposit rate by $2.4 \%$.

As mentioned, the initial shock directly increases the probability that an individual household will repay his loans in full. The extent of such increase is further magnified since the overall credit supply in the economy and the aggregate output in both states increase. ${ }^{24}$ Consequently, the values of all banks' risk-weighted assets rise. This in turn implies that the marginal benefit of higher profitability in terms of suffering less capital violation penalties for all banks is lower. Thus, banks revise their optimal level of profits downward in order to suffer lower default penalties. This directly worsens their capital position. Given lower profitability, bank $\gamma$ are able to adopt a more conservative position in both states. The same is true for banks $\delta$ and $\tau$ in the bad state. However, the negative portfolio reallocation effect on banks $\delta$ 's and $\tau$ 's profitability in the good state is so strong that they have to adopt a riskier position to be able to achieve the targeted profitability level.

\section{Robustness Check: The effect of an expansionary monetary policy under alternative initial conditions}

In section 4, we analysed the effect of an expansionary monetary policy on the economic system based on a given value of the parameters $u_{s, 2}, \forall s \in S$, in the reduced-form equation (12). We have already noted that these parameters are important because they capture the degree of responsiveness of aggregate economic activities, as measured by GDP, to changes in financial variables of the model. Put differently, they represent the multiplier effect of changes in the overall credit supply in the economy with respect to aggregate output in the subsequent period. Thus, in this section, we provide a robustness check for the result of one of the comparative statics that we obtained in the previous section, i.e. a positive monetary policy shock, by studying the sensitivity of the impact of the shock on the economy as we simultaneously vary the value of the parameters $u_{s, 2}, \forall s \in S$. In doing so, we re-do another two independent comparative static exercises analogous to that shown in section 4.1, assuming instead that the value of the two parameters is 0 in the first and 0.05 in the second. Moreover, in order to maintain the same 'initial' equilibrium values of all endogenous variables across the these comparative statics, the values of autonomous part of $(\log )$ GDP (i.e. $u_{s, 1}, \forall s \in S$ ) are adjusted accordingly. In this way, the initial equilibrium values of GDP in both states are the same across all comparative static exercises. Figure 2 reports the percentage changes in key variables in response to an expansionary monetary policy (i.e. an increase in base money from 69.28 to 71.28 trillion pounds) under different values of $u_{s, 2}, \forall s \in S$, i.e. $0,0.05$, and 0.1.

Assuming the same positive monetary policy shock, the remainder of this section analyses how the response of key endogenous variables changes as we simultaneously increase the value of $u_{s, 2}, \forall s \in S$. Given a higher value of these parameters, other things constant, an increase in same amount of aggregate credit supply results in a larger increase in GDP in both states of the subsequent period, causing, in turn, households' default probability in the loan market to decrease more precipitously. This implies that, a higher value of these two parameters, other things constant, results in a higher expected rate of return from extending consumer loans for all banks. Thus, all banks increase their credit supply even more, causing the extent of increase in the aggregate credit supply in the economy to rise. This implies that extent of increase in GDP and the probability that households will repay in full in both states increases.

\footnotetext{
${ }^{24}$ As can be seen from table IX, GDP in the bad state rise by $2.03 \%, 2.02 \%$ of which is from the direct effect and $0.01 \%$ of which is from the indirect effect via higher aggregate supply of credit in the economy.
} 

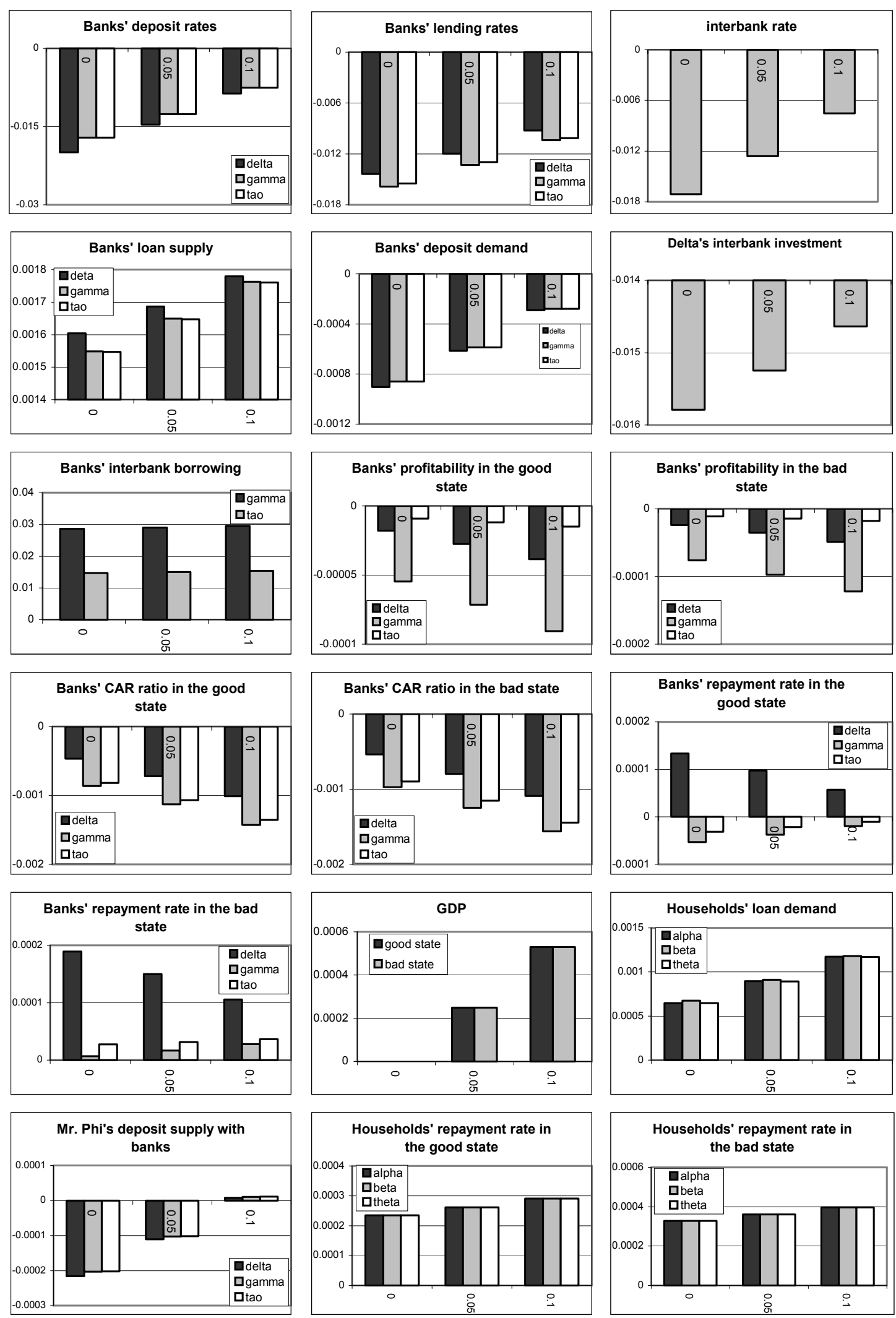

Figure 2: $\%$ changes in key variables in response to an expansionary monetary policy under different values of $u_{s, 2}, \forall s \in S$ (i.e. $0,0.05,0.1$ ). 
Since all banks supply more credit, they need more funds to finance their higher investment. Thus, although, as explained in section 4.1, all banks respond to a positive monetary policy shock by decreasing their demand for deposits, the rate of such decrease falls. This in turn implies that the extent of decline in every bank's deposit rates has to be smaller as well. Moreover, banks $\gamma$ and $\tau$, which are net borrowers in the interbank market, demand an even greater amount of interbank borrowing. This causes a smaller decline in the interbank rate.

Because of the bigger multiplier effect of GDP with respect to aggregate credit extension in both states, the increase in all household borrowers' loan demand is greater. This effect is strong enough to reduce the rate of decrease in every banks' lending rates. Moreover, Mr. $\phi$ increases his deposit supply to banks, thus increasing their available investment funds. This causes not only the percentage increase in bank $\delta$ 's investment in the loan market to be higher but also the percentage decrease in its interbank investment to be lower.

Because the extent of decrease in households' default probability in both states is bigger, the values of every bank's risk-weighted assets grow by an even larger amount. This reduces the incentive for banks to achieve higher profitability even further. Consequently, all banks choose to achieve an even lower optimal level of profits, exacerbating the extent of decline in the capital violation penalties (recall that profits enter the numerator of the capital adequacy requirements). Given that the targeted level of profits decreases more substantially, banks $\gamma$ and $\tau$ choose a relatively more conservative portfolio, though such position is still riskier compared to their initial equilibrium positions. We observe, however, that the percentage increase in bank $\delta$ 's probability of default declines. This is because the negative pressure from the portfolio reallocation effect is relatively stronger for bank $\delta$.

In sum, we observe that the effect of an expansionary monetary policy on the economic system is, in general, directionally the same under alternative values of $u_{s, 2}, \forall s \in S$. However, the magnitude of its effect on the banking sector and the real economy is found to be stronger as we increase the value of the parameters. This is because, in such a case, the 'multiplier' effect from changing aggregate credit condition to default and ultimately to aggregate output is stronger.

\section{Conclusion}

This is the first attempt at calibration, to bring the model to real (UK) data, that we have made; the programme of work that we are following is just beginning to span the chasm between pure theory and practical empirical modelling. Nevertheless there is a long way yet to go. For example, this remains a two-period model only, in which banks take decisions in period one, e.g. determining their holdings of loans and deposits, on the basis of expectations of the potential states in period two; they then are stuck with their decisions in period two. In a longer period model, the outcome in period two would cause banks to revise their expectations of states in period three (e.g. as in a Markov switching model), thereby causing them dynamically to revise their loans/deposits in period two, and so on. Also, for a variety of reasons, mostly connected with data availability, we took the value of each bank's trading books (its investments) as a constant throughout.

Although we have based this exercise on real UK data, it remains a simulation. It does not provide an independent check whether our model can capture the main time series properties of the major UK banks. Trying to do this latter, and also to work out some way to lengthen the number of time periods in the model, without making the model far too unwieldy to solve are priorities for future research. In particular, this analysis reveals how complex, and complicated, 
default is as an institution, which is one reason why it rarely figures in other model.

Given these constraints, the focus of this exercise was on adjustments in the interbank market, and in the relative interest rates on deposits and loans; hence, in part via changes in bank margins, this fed back into changes in bank profits, capital and CARs. Like most other empirical research in this field, we do not find much serious contagion occurring via the interbank market with our arbitrarily chosen set of banks. Note that we could re-do this exercise for any other pair of UK banks (with a third residual banking sector). One result that practitioners will have expected, but not perhaps academics, is that contagion is much diminished if the Central Bank targets interest rates rather than a fixed time path for base money. We intend to write this latter up as a separate academic article.

Perhaps the most striking result is the sensitivity of banking profitability (in a bad state) to changes in the 'default penalty' on banks, see Table VII. We think of this as measuring the general risk aversion of banks, which is a function of the banks' own conservatism, and concern for regulation, interacting with externally-imposed discipline from markets and from the regulatory/supervisory regime. The greater the risks that bank managers are prepared to run, in pursuit of profit, the greater the probability of default in a bad state.

No doubt a glimpse of the obvious, but a problem is that such risk aversion is not objectively measurable. Indeed, but it is crucial, at least in our models. What this means is that to run models where default matters, the model builders will have to depend on the regulators/supervisors to give them some input, e.g. in the form of rankings, on the relative appetite for risk of the various banks involved.

It is not, however, clear whether this is a 'good' result, since it would require all concerned to focus on the really important issues, or a 'bad' result since it reveals just how difficult quantification and modelling continues to be in this field.

\section{Appendix}

\begin{tabular}{|c|c|c|c|c|c|c|c|c|c|c|c|c|c|c|c|c|c|c|}
\hline \multicolumn{19}{|c|}{ Table A1: } \\
\hline \multicolumn{19}{|c|}{ (Central Bank sets base money) } \\
\hline & $r^{\delta}$ & $r^{\gamma}$ & $r^{\tau}$ & $r_{d}^{\delta}$ & $r_{d}^{\gamma}$ & $r_{d}^{\tau}$ & $\rho$ & $\overline{m^{\delta}}$ & $\bar{m}^{\gamma}$ & $\bar{m}^{\tau}$ & $\mu_{d}^{\delta}$ & $\mu_{d}^{\gamma}$ & $\mu_{d}^{\tau}$ & $d^{\delta}$ & $\mu^{\gamma}$ & $\mu^{\tau}$ & $\widetilde{R_{i}}$ & $\widetilde{R_{i i}}$ \\
\hline$M$ & - & - & - & - & - & - & - & + & + & + & - & - & - & - & + & + & $\bar{\sim}$ & + \\
\hline$z_{\delta 1}$ & - & - & - & - & - & - & - & + & + & + & + & - & - & + & + & + & - & + \\
\hline$z_{\gamma 1}$ & - & - & - & - & - & - & - & + & + & + & - & + & - & - & - & + & $\bar{\approx}$ & $\stackrel{+}{\approx}$ \\
\hline$e_{0}^{\delta}$ & - & - & - & - & - & - & - & + & + & + & $\bar{\approx}$ & $\bar{\approx}$ & $\bar{\approx}$ & + & + & + & $\bar{z}$ & $\stackrel{+}{\approx}$ \\
\hline$\lambda_{i i}^{b}$ & + & - & - & + & - & - & - & - & + & $\stackrel{+}{\sim}$ & + & - & - & + & + & + & + & + \\
\hline$\overline{\lambda_{k i i}^{b}}$ & $\underset{\approx}{+}$ & $\stackrel{+}{\approx}$ & $\approx$ & $\bar{\approx}$ & $\approx$ & $\approx$ & $\bar{\approx}$ & $\approx$ & $\widetilde{\sim}$ & $\stackrel{+}{\approx}$ & $\bar{\tau}$ & $\bar{\approx}$ & $\bar{\approx}$ & $\approx$ & $\bar{\approx}$ & $\stackrel{+}{\approx}$ & $\stackrel{+}{\tilde{z}}$ & $\bar{\approx}$ \\
\hline $\bar{\omega}$ & + & - & $\stackrel{+}{\approx}$ & + & $\stackrel{+}{\approx}$ & $\stackrel{+}{\approx}$ & $\stackrel{+}{\approx}$ & $\bar{\approx}$ & $\stackrel{+}{*}$ & $\stackrel{+}{\approx}$ & $\stackrel{+}{\approx}$ & $\stackrel{+}{*}$ & $\underset{\approx}{+}$ & $\stackrel{+}{\approx}$ & + & $\stackrel{+}{*}$ & $\stackrel{+}{\sim}$ & + \\
\hline$u_{1}$ & + & + & + & + & + & + & + & + & + & + & + & + & + & + & + & + & $\bar{\sim}$ & + \\
\hline \multicolumn{19}{|c|}{ Note: $+(-):$ substantial increase (decrease), } \\
\hline+( & & & & & & & & & & & & & & & & & & \\
\hline
\end{tabular}




\begin{tabular}{|c|c|c|c|c|c|c|c|c|c|c|c|c|c|c|c|c|c|}
\hline \multicolumn{18}{|c|}{ Table A1 (continue): } \\
\hline \multicolumn{18}{|c|}{ (Central Bank sets base money) } \\
\hline & $v_{i}^{\delta}$ & $v_{i i}^{\delta}$ & $v^{\delta}$ & $v_{i}^{\gamma}$ & $v_{i i}^{\gamma}$ & $v^{\gamma}$ & $\overline{v_{i}^{\tau}}$ & $\overline{v_{i i}^{\tau}}$ & $v^{\tau}$ & $\Pi^{\delta}$ & $\Pi^{\gamma}$ & $\Pi^{\tau}$ & $\Pi^{B}$ & $\pi_{i}^{\delta}$ & $\pi_{i i}^{\delta}$ & $\pi_{i}^{\gamma}$ & $\pi_{i i}^{\gamma}$ \\
\hline$M$ & $\stackrel{+}{+}$ & $+\underset{\sim}{+}$ & + & $\bar{\tau}$ & + & $\bar{\sim}$ & $\bar{\tau}$ & + & $\bar{\sim}$ & + & - & - & + & $\bar{\tau}$ & $\bar{\sim}$ & $\bar{\tau}$ & $\bar{\tau}$ \\
\hline$z_{\delta 1}$ & + & + & + & $\approx$ & + & $\approx$ & $\approx$ & + & $\tilde{\tau}$ & + & - & - & + & - & - & - & - \\
\hline$z_{\gamma 1}$ & $\stackrel{+}{\approx}$ & + & $\stackrel{+}{\approx}$ & $\bar{\tau}$ & $\stackrel{+}{\approx}$ & $\bar{\approx}$ & $\bar{\approx}$ & $\stackrel{+}{\approx}$ & $\bar{\approx}$ & + & - & - & + & $\bar{\approx}$ & $\bar{\approx}$ & $\bar{\approx}$ & - \\
\hline$e_{0}^{\delta}$ & $\stackrel{+}{\approx}$ & $\stackrel{+}{\approx}$ & $\stackrel{+}{\approx}$ & $\bar{\tau}$ & + & $\bar{\approx}$ & $\bar{\approx}$ & + & $\bar{\tau}$ & + & - & - & + & $\bar{\tau}$ & $\bar{\tau}$ & $\bar{\approx}$ & $\bar{\approx}$ \\
\hline$\lambda_{i i}^{b}$ & $\stackrel{+}{\sim}$ & + & $\stackrel{+}{\sim}$ & + & + & + & $\stackrel{+}{\approx}$ & $\stackrel{+}{\approx}$ & + & - & + & + & + & + & - & + & - \\
\hline$\lambda_{k i i}^{b}$ & $\stackrel{+}{\approx}$ & $\approx$ & $\stackrel{+}{\approx}$ & $\stackrel{+}{\approx}$ & $\bar{\approx}$ & $\approx$ & $\underset{\approx}{+}$ & $\bar{\tau}$ & $\approx$ & $\underset{\approx}{+}$ & $\underset{\approx}{+}$ & $\underset{\approx}{+}$ & $\underset{\approx}{+}$ & $\stackrel{+}{\approx}$ & + & $\stackrel{+}{\approx}$ & + \\
\hline $\bar{\omega}$ & $\approx$ & $\bar{\approx}$ & $\bar{\approx}$ & $\underset{\approx}{+}$ & $\stackrel{+}{\approx}$ & $\underset{\approx}{+}$ & $\underset{\approx}{+}$ & $\underset{\approx}{+}$ & $\underset{\approx}{+}$ & - & - & - & - & - & - & - & - \\
\hline$u_{1}$ & - & + & - & + & + & + & $\bar{\tau}$ & + & $\stackrel{+}{\approx}$ & - & + & + & - & $\bar{\tau}$ & - & $\bar{\sim}$ & $\bar{\tau}$ \\
\hline \multicolumn{18}{|c|}{ Note: $v^{b} \equiv p v_{i}^{b}+(1-p) v_{i i}^{b}, b \in\{\gamma, \delta, \tau\}$ and } \\
\hline$\Pi^{B}$ & & & & & & & & & & & & & & & & & \\
\hline
\end{tabular}

Table A1 (continue):

(Central Bank sets base money)

\begin{tabular}{|c|c|c|c|c|c|c|c|c|c|c|c|c|c|c|c|c|c|c|}
\hline \multicolumn{19}{|c|}{ (Central Bank sets base money) } \\
\hline & $\pi_{i}^{\tau}$ & $\pi_{i i}^{\tau}$ & $e_{i}^{\delta}$ & $e_{i i}^{\delta}$ & $e_{i}^{\gamma}$ & $e_{i i}^{\gamma}$ & $e_{i}^{\tau}$ & $e_{i i}^{\tau}$ & $k_{i}^{\delta}$ & $k_{i i}^{\delta}$ & $k^{\delta}$ & $k_{i}^{\gamma}$ & $k_{i i}^{\gamma}$ & $k^{\gamma}$ & $k_{i}^{\tau}$ & $k_{i i}^{\tau}$ & $k^{\tau}$ & $k$ \\
\hline $\bar{M}$ & $\bar{\approx}$ & $\bar{\approx}$ & $\bar{\approx}$ & $\bar{\approx}$ & $\bar{\approx}$ & $\bar{\approx}$ & $\bar{\approx}$ & $\bar{\approx}$ & - & - & - & - & - & - & - & - & - & - \\
\hline$z_{\delta 1}$ & $\bar{\approx}$ & $\bar{\approx}$ & $\approx$ & $\approx$ & $\bar{\approx}$ & - & $\bar{\approx}$ & $\approx$ & - & - & - & - & - & - & - & - & - & - \\
\hline$z_{\gamma 1}$ & $\bar{\approx}$ & $\bar{\approx}$ & $\approx$ & $\bar{\approx}$ & $\bar{\approx}$ & $\bar{\approx}$ & $\approx$ & $\approx$ & - & - & - & - & - & - & - & - & - & - \\
\hline$e_{0}^{\delta}$ & $\bar{\tau}$ & $\bar{\sim}$ & $\tilde{+}$ & $\tilde{+}$ & $\tilde{\tau}$ & $\tilde{\sim}$ & $\tilde{\widetilde{z}}$ & $\tilde{\widetilde{z}}$ & + & + & + & - & - & - & - & - & - & - \\
\hline$\lambda_{i i}^{b}$ & $\stackrel{+}{\approx}$ & - & $\stackrel{+}{\approx}$ & - & $\underset{\approx}{*}$ & - & $\stackrel{+}{\approx}$ & 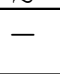 & $\stackrel{+}{\approx}$ & - & - & $\stackrel{+}{\approx}$ & - & - & $\stackrel{+}{\approx}$ & - & - & - \\
\hline$\lambda_{k i i}^{b}$ & $\approx$ & + & $\approx$ & $\stackrel{+}{\approx}$ & $\approx$ & + & $\approx$ & $\stackrel{+}{\approx}$ & $\stackrel{+}{\approx}$ & + & $\stackrel{+}{\approx}$ & $\stackrel{+}{\approx}$ & + & $\stackrel{+}{\approx}$ & $\stackrel{+}{\approx}$ & $\stackrel{+}{\approx}$ & $\stackrel{+}{\approx}$ & $\underset{\approx}{+}$ \\
\hline$\overline{\bar{\omega}}$ & - & - & $\bar{\approx}$ & $\bar{\approx}$ & - & - & $\approx$ & $\approx$ & - & - & - & - & - & - & - & - & - & - \\
\hline$u_{1}$ & $\bar{\approx}$ & $\bar{\approx}$ & $\bar{\approx}$ & $\bar{\approx}$ & $\bar{\approx}$ & - & $\bar{\approx}$ & $\approx$ & - & - & - & - & - & - & - & - & - & - \\
\hline
\end{tabular}

\begin{tabular}{|c|c|c|c|c|c|c|c|c|c|c|c|c|c|c|}
\hline & & & & & & abl & $\mathbf{A} 1$ & (con & inue & & & & & \\
\hline & & & & & ent & al 1 & $\overline{a n k}$ & sets & ase & mon & & & & \\
\hline & $\mu^{\beta^{\delta}}$ & $\mu^{\alpha^{\gamma}}$ & $\mu^{\theta^{\tau}}$ & $d_{\delta}^{\phi}$ & $d_{\gamma}^{\phi}$ & $d_{\tau}^{\phi}$ & $v_{i \gamma}^{\alpha}$ & $v_{i i \gamma}^{\alpha}$ & $\overline{v_{i \delta}^{\beta}}$ & $v_{i i \delta}^{\beta}$ & $v_{i \tau}^{\theta}$ & $v_{i i \tau}^{\theta}$ & $G D P_{i}$ & $G D P_{i i}$ \\
\hline $\bar{M}$ & + & + & + & $\stackrel{+}{\approx}$ & $\stackrel{+}{\approx}$ & $\stackrel{+}{\approx}$ & + & + & + & + & + & + & + & + \\
\hline$z_{\delta 1}$ & + & + & + & + & $\stackrel{+}{\sim}$ & $\stackrel{\sim}{\sim}$ & + & + & + & + & + & + & + & + \\
\hline$z_{\gamma 1}$ & + & + & + & $\stackrel{+}{\approx}$ & + & $\stackrel{+}{\approx}$ & + & + & + & + & + & + & + & + \\
\hline$e_{0}^{\delta}$ & + & + & + & $\underset{\sim}{+}$ & + & + & + & + & + & + & + & + & + & + \\
\hline$\lambda_{i i}^{b}$ & - & $\bar{\approx}$ & $\approx$ & $\stackrel{+}{\approx}$ & $\bar{\approx}$ & $\bar{\tau}$ & $\bar{\tau}$ & $\bar{\sim}$ & $\bar{\tau}$ & $\bar{\tau}$ & $\bar{\tau}$ & $\bar{\tau}$ & $\bar{\tau}$ & $\bar{\approx}$ \\
\hline$\lambda_{k i i}^{b}$ & $\bar{\sim}$ & $\bar{\tau}$ & $\bar{\tau}$ & $\bar{\tau}$ & $\bar{\tau}$ & $\bar{\tau}$ & $\bar{\tau}$ & $\bar{\tau}$ & $\bar{\sim}$ & $\bar{\sim}$ & $\bar{\tau}$ & $\bar{\tau}$ & $\bar{\sim}$ & $\bar{\sim}$ \\
\hline$\overline{\bar{\omega}}$ & $\stackrel{+}{\approx}$ & $\stackrel{+}{\approx}$ & $\stackrel{+}{\approx}$ & $\stackrel{+}{\approx}$ & $\stackrel{+}{\approx}$ & $\stackrel{+}{\approx}$ & $\stackrel{+}{\approx}$ & $\stackrel{+}{\approx}$ & $\stackrel{+}{\approx}$ & $\stackrel{+}{\approx}$ & $\stackrel{+}{\approx}$ & $\stackrel{+}{\approx}$ & $\stackrel{+}{\approx}$ & $\stackrel{+}{\approx}$ \\
\hline$u_{1}$ & + & + & + & $\stackrel{+}{\approx}$ & $\stackrel{+}{\approx}$ & $\stackrel{+}{\approx}$ & $\underset{\approx}{*}$ & + & $\stackrel{+}{\approx}$ & + & $\stackrel{+}{\approx}$ & + & $\stackrel{+}{\approx}$ & + \\
\hline
\end{tabular}




\begin{tabular}{|c|c|c|c|c|c|c|c|c|c|c|c|c|c|c|c|c|c|c|}
\hline \multicolumn{19}{|c|}{ Table A2: } \\
\hline \multicolumn{19}{|c|}{ (Central Bank sets the interbank rate) } \\
\hline & $r^{\delta}$ & $r^{\gamma}$ & $r^{\tau}$ & $r_{d}^{\delta}$ & $r_{d}^{\gamma}$ & $r_{d}^{\tau}$ & $M$ & $\bar{m}^{\delta}$ & $\bar{m}^{\gamma}$ & $\bar{m}^{\tau}$ & $\mu_{d}^{\delta}$ & $\mu_{d}^{\gamma}$ & $\mu_{d}^{\tau}$ & $d^{\delta}$ & $\mu^{\gamma}$ & $\mu^{\tau}$ & $\widetilde{R}_{i}$ & $\widetilde{R}_{i i}$ \\
\hline$z_{\delta 1}$ & - & $\bar{z}$ & $\bar{z}$ & $\stackrel{+}{\approx}$ & $\approx$ & $\approx$ & - & $\stackrel{+}{\approx}$ & $\stackrel{+}{\approx}$ & $\stackrel{+}{\approx}$ & + & $\stackrel{+}{\approx}$ & $\underset{\approx}{*}$ & + & + & $\stackrel{+}{\approx}$ & $\approx$ & $\underset{\approx}{+}$ \\
\hline$z_{\gamma 1}$ & $\approx$ & $\approx$ & $\approx$ & $\approx$ & $\approx$ & $\approx$ & - & $\approx$ & $\approx$ & $\approx$ & $\approx$ & + & $\approx$ & $\approx$ & - & $\approx$ & $\approx$ & $\approx$ \\
\hline$e_{0}^{\delta}$ & + & $\stackrel{+}{\approx}$ & $\stackrel{+}{\approx}$ & $\bar{\approx}$ & $\approx$ & $\approx$ & - & $\bar{\approx}$ & $\bar{\approx}$ & $\bar{\sim}$ & $\bar{\approx}$ & $\bar{\approx}$ & $\bar{\approx}$ & + & - & $\bar{\approx}$ & $\approx$ & $\bar{\approx}$ \\
\hline$\lambda_{i i}^{b}$ & + & + & + & + & $\approx$ & $\approx$ & - & - & - & - & + & $\bar{\approx}$ & $\bar{\approx}$ & + & - & - & $\underset{\approx}{+}$ & + \\
\hline$\lambda_{k i i}^{b}$ & $\stackrel{+}{\approx}$ & $\stackrel{+}{\approx}$ & $\stackrel{+}{\approx}$ & $\bar{\approx}$ & $\approx$ & $\approx$ & $\bar{\approx}$ & $\bar{\approx}$ & $\bar{\approx}$ & $\bar{\approx}$ & $\approx$ & $\approx$ & $\approx$ & $\stackrel{+}{\approx}$ & $\bar{\approx}$ & $\approx$ & $\stackrel{+}{\approx}$ & $\bar{\approx}$ \\
\hline $\bar{\omega}$ & $\bar{\approx}$ & - & $\approx$ & + & $\approx$ & $\approx$ & + & $\stackrel{+}{\approx}$ & $\underset{\approx}{+}$ & $\underset{\approx}{+}$ & $\underset{\approx}{+}$ & $\stackrel{+}{\approx}$ & $\underset{\approx}{+}$ & $\bar{\approx}$ & + & + & $\stackrel{+}{\approx}$ & $\underset{\approx}{+}$ \\
\hline$u_{1}$ & - & - & - & + & $\approx$ & $\approx$ & + & + & + & + & + & + & + & - & + & + & $\bar{\approx}$ & + \\
\hline
\end{tabular}

\begin{tabular}{|c|c|c|c|c|c|c|c|c|c|c|c|c|c|c|c|c|c|}
\hline \multicolumn{18}{|c|}{ Table A2 (continue): } \\
\hline \multicolumn{18}{|c|}{ (Central Bank sets the interbank rate) } \\
\hline & $v_{i}^{\delta}$ & $v_{i i}^{\delta}$ & $v^{\delta}$ & $v_{i}^{\gamma}$ & $v_{i i}^{\gamma}$ & $v^{\gamma}$ & $v_{i}^{\tau}$ & $v_{i i}^{\tau}$ & $v^{\tau}$ & $\Pi^{\delta}$ & $\Pi^{\gamma}$ & $\Pi^{\tau}$ & $\Pi^{B}$ & $\pi_{i}^{\delta}$ & $\pi_{i i}^{\delta}$ & $\pi_{i}^{\gamma}$ & $\pi_{i i}^{\gamma}$ \\
\hline$z_{\delta 1}$ & + & $\bar{\approx}$ & + & $\approx$ & $\stackrel{+}{\approx}$ & $\approx$ & $\approx$ & $\stackrel{+}{\approx}$ & $\approx$ & - & $\bar{\approx}$ & $\approx$ & - & - & - & $\approx$ & $\approx$ \\
\hline$z_{\gamma 1}$ & $\approx$ & $\approx$ & $\approx$ & $\approx$ & $\approx$ & $\approx$ & $\approx$ & $\approx$ & $\approx$ & $\approx$ & $\approx$ & $\approx$ & $\approx$ & $\approx$ & $\approx$ & $\approx$ & $\approx$ \\
\hline$e_{0}^{\delta}$ & $\stackrel{+}{\approx}$ & $\bar{\approx}$ & $\stackrel{+}{\approx}$ & $\approx$ & $\approx$ & $\approx$ & $\approx$ & $\approx$ & $\approx$ & + & $\stackrel{+}{\approx}$ & $\stackrel{+}{\approx}$ & + & $\bar{\approx}$ & $\bar{\approx}$ & $\approx$ & $\approx$ \\
\hline$\lambda_{i i}^{b}$ & $\approx$ & + & $\underset{\approx}{+}$ & $\stackrel{+}{\approx}$ & + & + & $\underset{\approx}{+}$ & + & + & - & + & + & + & $\stackrel{+}{\approx}$ & - & $\underset{\approx}{+}$ & - \\
\hline$\lambda_{k i i}^{b}$ & $\stackrel{+}{\approx}$ & $\approx$ & $\stackrel{+}{\approx}$ & $\approx$ & $\bar{\approx}$ & $\bar{\approx}$ & $\stackrel{+}{\approx}$ & $\bar{\approx}$ & $\approx$ & $\stackrel{+}{\approx}$ & $\underset{\approx}{+}$ & $\stackrel{+}{\approx}$ & $\stackrel{+}{\approx}$ & $\approx$ & + & $\approx$ & + \\
\hline $\bar{\omega}$ & $\bar{\approx}$ & $\bar{\approx}$ & $\bar{\approx}$ & $\stackrel{+}{\approx}$ & $\underset{\approx}{+}$ & $\underset{\approx}{+}$ & $\stackrel{+}{\approx}$ & $\stackrel{+}{\approx}$ & $\underset{\approx}{+}$ & - & - & - & - & - & - & - & - \\
\hline$u_{1}$ & - & + & $\bar{\approx}$ & $\bar{\approx}$ & + & $\underset{\approx}{+}$ & $\bar{\approx}$ & + & $\stackrel{+}{\sim}$ & - & - & - & - & - & - & - & - \\
\hline
\end{tabular}

\begin{tabular}{|c|c|c|c|c|c|c|c|c|c|c|c|c|c|c|c|c|c|c|}
\hline \multicolumn{19}{|c|}{ Table A2 (continue): } \\
\hline \multicolumn{19}{|c|}{ (Central Bank sets the interbank rate) } \\
\hline & $\pi_{i}^{\tau}$ & $\pi_{i i}^{\tau}$ & $e_{i}^{\delta}$ & $e_{i i}^{\delta}$ & $e_{i}^{\gamma}$ & $e_{i i}^{\gamma}$ & $e_{i}^{\tau}$ & $e_{i i}^{\tau}$ & $k_{i}^{\delta}$ & $k_{i i}^{\delta}$ & $k^{\delta}$ & $k_{i}^{\gamma}$ & $k_{i i}^{\gamma}$ & $k^{\gamma}$ & $k_{i}^{\tau}$ & $k_{i i}^{\tau}$ & $k^{\tau}$ & $k$ \\
\hline$z_{\delta 1}$ & $\approx$ & $\approx$ & $\bar{\tau}$ & $\bar{\approx}$ & $\approx$ & $\approx$ & $\approx$ & $\approx$ & - & - & - & $\bar{\approx}$ & $\bar{z}$ & $\bar{\approx}$ & $\bar{\approx}$ & $\bar{\approx}$ & $\bar{\approx}$ & - \\
\hline$z_{\gamma 1}$ & $\approx$ & $\approx$ & $\approx$ & $\approx$ & $\approx$ & $\approx$ & $\approx$ & $\approx$ & $\approx$ & $\approx$ & $\approx$ & $\approx$ & $\approx$ & $\approx$ & $\approx$ & $\approx$ & $\approx$ & $\approx$ \\
\hline$\frac{1}{e_{0}^{\delta}}$ & $\approx$ & $\approx$ & + & + & $\approx$ & $\approx$ & $\approx$ & $\approx$ & + & + & + & + & + & + & $\stackrel{\sim}{\sim}$ & $\stackrel{+}{\sim}$ & + & + \\
\hline$\lambda_{i i}^{b}$ & $\stackrel{+}{\approx}$ & - & $\approx$ & - & $\approx$ & - & $\approx$ & - & + & - & + & $\tilde{+}$ & $\sim$ & $\tilde{-}$ & + & $\sim$ & - & - \\
\hline$\lambda_{k i i}^{b}$ & $\approx$ & + & $\approx$ & $\underset{\approx}{+}$ & $\approx$ & + & $\approx$ & $\stackrel{+}{\approx}$ & $\underset{\approx}{+}$ & $\underset{\approx}{+}$ & $\underset{\approx}{+}$ & $\stackrel{+}{\approx}$ & + & $\underset{\approx}{+}$ & $\underset{\approx}{+}$ & $\underset{\approx}{+}$ & $\stackrel{+}{\approx}$ & $\stackrel{+}{\approx}$ \\
\hline$\overline{\bar{\omega}}$ & - & - & $\bar{\tau}$ & $\approx$ & - & - & $\bar{\sim}$ & $\bar{z}$ & - & - & - & - & - & - & - & - & - & - \\
\hline$u_{1}$ & - & - & $\bar{\approx}$ & $\bar{\approx}$ & - & - & $\bar{\approx}$ & $\bar{\approx}$ & - & - & - & - & - & - & - & - & - & - \\
\hline \multicolumn{19}{|c|}{ Note: $k^{b} \equiv p k_{i}^{b}+(1-p) k_{i i}^{b}, b \in\{\gamma, \delta, \tau\}$ and } \\
\hline & & & & & & & & & & & & & & & & & & \\
\hline
\end{tabular}




\begin{tabular}{|c|c|c|c|c|c|c|c|c|c|c|c|c|c|c|}
\hline \multicolumn{15}{|c|}{ Table A2 (continue): } \\
\hline \multicolumn{15}{|c|}{ (Central Bank sets the interbank rate) } \\
\hline & $\mu^{\beta^{\delta}}$ & $\mu^{\alpha^{\gamma}}$ & $\mu^{\theta^{\tau}}$ & $d_{\delta}^{\phi}$ & $d_{\gamma}^{\phi}$ & $d_{\tau}^{\phi}$ & $v_{i \gamma}^{\alpha}$ & $v_{i i \gamma}^{\alpha}$ & $v_{i \delta}^{\beta}$ & $v_{i i \delta}^{\beta}$ & $v_{i \tau}^{\theta}$ & $v_{i i \tau}^{\theta}$ & $G D P_{i}$ & $G D P_{i i}$ \\
\hline$z_{\delta 1}$ & $\stackrel{+}{\approx}$ & $\stackrel{+}{\approx}$ & $\underset{\approx}{+}$ & + & $\stackrel{+}{\approx}$ & $\stackrel{+}{\approx}$ & $\stackrel{+}{\approx}$ & $\stackrel{+}{\approx}$ & $\stackrel{+}{\approx}$ & $\stackrel{+}{\approx}$ & $\stackrel{+}{\approx}$ & $\stackrel{+}{\approx}$ & $\stackrel{+}{\approx}$ & $\stackrel{+}{\approx}$ \\
\hline$z_{\gamma 1}$ & $\approx$ & $\approx$ & $\approx$ & $\approx$ & + & $\approx$ & $\approx$ & $\approx$ & $\approx$ & $\approx$ & $\approx$ & $\approx$ & $\approx$ & $\approx$ \\
\hline$e_{0}^{\delta}$ & $\bar{\approx}$ & $\bar{\approx}$ & $\bar{\approx}$ & $\bar{\approx}$ & $\bar{\approx}$ & $\bar{\approx}$ & $\bar{\approx}$ & $\bar{\approx}$ & $\bar{\approx}$ & $\bar{\approx}$ & $\bar{\approx}$ & $\bar{\approx}$ & $\bar{\approx}$ & $\bar{\approx}$ \\
\hline$\overline{\lambda_{i i}^{b}}$ & - & - & - & $\stackrel{+}{\approx}$ & $\bar{\approx}$ & $\bar{\approx}$ & $\bar{\approx}$ & - & $\bar{\approx}$ & - & $\bar{\approx}$ & - & - & - \\
\hline$\lambda_{k i i}^{b}$ & $\bar{\approx}$ & $\bar{\approx}$ & $\bar{\approx}$ & $\bar{\approx}$ & $\approx$ & $\bar{\approx}$ & $\approx$ & $\bar{\approx}$ & $\bar{\approx}$ & $\bar{\approx}$ & $\approx$ & $\bar{\approx}$ & $\bar{\approx}$ & $\bar{\approx}$ \\
\hline$\overline{\bar{\omega}}$ & $\underset{\approx}{+}$ & $\stackrel{+}{\approx}$ & $\underset{\approx}{+}$ & $\stackrel{+}{\approx}$ & $\underset{\approx}{+}$ & $\underset{\approx}{+}$ & $\stackrel{+}{\approx}$ & $\stackrel{+}{\approx}$ & $\underset{\approx}{+}$ & $\stackrel{+}{\approx}$ & $\underset{\approx}{+}$ & $\underset{\approx}{+}$ & $\underset{\approx}{+}$ & $\underset{\approx}{+}$ \\
\hline$u_{1}$ & + & + & + & $\underset{\approx}{+}$ & $\underset{\approx}{+}$ & $\stackrel{+}{\approx}$ & $\stackrel{+}{\approx}$ & + & $\underset{\approx}{+}$ & + & $\underset{\approx}{+}$ & + & $\underset{\approx}{+}$ & + \\
\hline
\end{tabular}

\section{References}

[1] Bhattacharya, S., Goodhart, C.A.E., Sunirand, P., Tsomocos, D.P., 2003, Relative performance, banks and sequential contagion. mimeo, University of Oxford.

[2] Catarineu-Rabell, E., Jackson, P., Tsomocos, D.P., 2003, Procyclicality and the new Basel Accord-banks' choice of loan rating system. Economic Theory (forthcoming).

[3] Chrystal, A., Mizen, P., 2003, Consumption, money, and lending: a joint model for the UK household sector. Journal of Money Credit and Banking (forthcoming).

[4] Dubey, P., Shubik, M., 1978, The Non-cooperative equilibria of a closed trading economy with market supply and bidding strategies. Journal of Economic Theory, 17:1-20.

[5] Elsinger, H., Lehar, A., Summer, M., 2003, Risk assessment for banking systems. Oesterreichische Nationalbank (Austrian National Bank) Working paper no. 79.

[6] Goodhart, C.A.E, 1989, Money, Information and Uncertainty, $2^{\text {nd }}$ Edition (Macmillan: London).

[7] Goodhart, C.A.E., Sunirand, P., Tsomocos, D.P., 2003, A model to analyse financial fragility. Oxford Financial Research Centre Working Paper No. $2003 f e 13$.

[8] Goodhart, C.A.E., Sunirand, P., Tsomocos, D.P., 2004, A model to analyse financial fragility: Applications. Journal of Financial Stability (forthcoming).

[9] Shubik, M., 1999, The Theory of Money and Financial Institutions (Cambridge, Massachusetts: The MIT Press).

[10] Shubik, M., Tsomocos, D.P., 1992, A strategic market game with a mutual bank with fractional reserves and redemption in gold. Journal of Economics, 55(2):123-150.

[11] Shubik, M., Wilson, C., 1977, The optimal bankruptcy rule in a trading economy using fiat money. Journal of Economics, 37:337-354.

[12] Tsomocos, D.P., 2003a, Equilibrium analysis, banking and financial instability. Journal of Mathematical Economics, 39(5-6):619-655. 
[13] Tsomocos, D.P., 2003b, Equilibrium analysis, banking, contagion and financial fragility. Greek Economic Review 23.

[14] Tsomocos, D.P., Zicchino, L., 2004, On modelling endogenous probability of default. mimeo, Bank of England. 